\title{
A framework to evaluate the interoperability of information systems - measuring the maturity of the business process alignment
}

Article

Accepted Version

Creative Commons: Attribution-Noncommercial-No Derivative Works 4.0

Liu, L., Li, W., Aljohani, N. R., Lytras, M. D., Hassan, S.-U. and Nawaz, R. (2020) A framework to evaluate the interoperability of information systems - measuring the maturity of the business process alignment. International Journal of Information Management, 54. 102153. ISSN 0268-4012 doi: https://doi.org/10.1016/j.ijinfomgt.2020.102153 Available at https://centaur.reading.ac.uk/91545/

It is advisable to refer to the publisher's version if you intend to cite from the work. See Guidance on citing.

To link to this article DOI: http://dx.doi.org/10.1016/j.jijinfomgt.2020.102153

Publisher: Elsevier

All outputs in CentAUR are protected by Intellectual Property Rights law, including copyright law. Copyright and IPR is retained by the creators or other copyright holders. Terms and conditions for use of this material are defined in the End User Agreement. 


\section{www.reading.ac.uk/centaur}

\section{CentAUR}

Central Archive at the University of Reading

Reading's research outputs online 


\title{
A Framework to Evaluate the Interoperability of Information Systems -
}

\author{
Measuring the Maturity of the Business Process Alignment
}

\author{
Leo LIU, ${ }^{1}$ Weizi LI, ${ }^{2}$ Naif ALJOHANI, ${ }^{3}$ Miltiadis D. LYTRAS, ${ }^{4}$ Saeed-Ul HASSAN,,${ }^{5}$ Raheel NAWAZ ${ }^{1}$ \\ ${ }^{1}$ Business and Law, Manchester Metropolitan University, Manchester, M15 6BH, UK \\ ${ }^{2}$ Informatics Research Centre, University of Reading, Reading, RG6 6UD, UK
}

${ }^{3}$ Faculty of Computing and Information Technology, King Abdulaziz University, Jeddah, Kingdom of Saudi Arabia

${ }^{4}$ Deree College, The American College of Greece, Athens, Greece

${ }^{5}$ Department of Computer Science, Information Technology University, 346-B, Ferozepur Road, Lahore, Pakistan

\begin{abstract}
In the current socio-economic environment, to face challenges such as the emergence of new technologies, globalisation and increasing demands from their clients it is inevitable that enterprises will collaborate with others and progressively shift their boundaries. In this context, interoperability has become a prerequisite in the jigsaw of such collaboration. By definition, it is entities' ability to work together as an organisation. This ability spans a wide range of aspects, embracing both technical and business issues. Over the past decade, both the concept and the context of interoperability have been extended from a largely IT-focused domain to a businessfocused domain and the evaluation of interoperability has become a rising concern. An increasing number of studies have concentrated on not just digital but business aspects of human behaviour in the social environment. In general, the wider application domain is the assessment of the interoperability of information systems and processes in any organisation (especially medium and large) that needs multiple processes to interact effectively.
\end{abstract}

To deal with such concerns and pave the way to achievement of more effective collaborative goals in business, the concept of interoperability has been adopted to measure the efficiency and productivity of information systems' integration. More than twenty approaches have so far been adopted to evaluate this interoperability, however most are unable to assess it at the higher levels, such as at the pragmatic, process and social levels. Hence, we have conducted a three-phase study. Phase 1 reviewed existing interoperability evaluation approaches. To prove the concept, phase 2 proposed the concept of semiotic interoperability and its application to healthcare information systems. This article reports on the third phase of the study, a proposed framework with a group of metrics to measure interoperability from a new perspective - a semiotics perspective. The framework is named the Semiotic Interoperability Evaluation Framework (the SIEF) and has the ability to analyse, measure and assess the interoperability among business processes. The metrics derive from a feasibility study to investigate several interoperability barriers at a hospital. Next, the SIEF was applied in a case study and a detailed interoperability evaluation was conducted.

Keywords Interoperability Evaluation, Semiotic Interoperability, Information Sharing, Business Process 


\section{Introduction}

In the current socio-economic environment, to face challenges such as the emergence of new technologies, globalisation and increasing demands from their clients, enterprises inevitably collaborate with others and progressively shift their boundaries. To enhance their competitiveness, organisations seek to be more responsive, collaborative and agile. They tend to maximise their investment in digital innovation and support information-sharing not only among their digital systems but among their business processes (Agostinho et al., 2016; Anwaar et al., 2018; Yunus et al., 2018). Their need for increased productivity indicates that collaboration among their business processes will help them to achieve improved productivity and cost effectiveness (Chen et al., 2008; Qadir et al., 2018; Ayyaz et al., 2018). In addition, there may be many mission-critical systems left over from previous mergers and acquisitions that require better interoperability in order to enhance information utilisation (Romero \& Molina, 2011; Nawaz et al., 2010, 2013; Batista-Navarro et al., 2013; Thompson et al., 2013, 2017; Shao 2019). Successful collaboration provides instant operations for an organisation, which leads to optimisation of its decision-making processes (EN/ISO, 2003; Rahimi et al., 2016). Successful information-sharing also helps its stakeholders to respond to the changes (Kaye, 2003; Moon et al., 2018). Moreover, it improves the organisation's agility by giving it the flexibility to quickly adapt its information systems to accommodate growth and meet the business challenges that arise.

In this collaborative context, interoperability has become a prerequisite in the jigsaw of such collaboration. By definition, it is entities' ability to work together as an organisation. This spans a wide range of aspects, embracing both technical and business issues. Over the past decade, both the concept and the context of interoperability have been extended from a largely IT-focused to a business-focused domain, and its evaluation has become a growing concern. An increasing number of studies have concentrated on not just digital but business aspects of human behaviour in the social environment. To study the effectiveness of information-sharing among digital systems and business processes in responding to changes in market demand and technological innovation, LaVean (1980) introduced the concept of interoperability to measure the efficiency and productivity of information systems integration. Since then, more than twenty approaches have been created to evaluate interoperability, but this has raised a research question - what are the limitations of existing frameworks for the evaluation of interoperability?

To answer this question, our previous work, representing the first phase of this study (Liu et al., 2013), conducted a comparative review of existing interoperability evaluation approaches from six perspectives (physical, empirical, syntactic, semantic, pragmatic and social). The results reveal that most do not fully address interoperability issues at the pragmatic level, at which an organisation's business processes, policies, behaviour and culture are considered.

Consequently, in the second phrase of this study we proposed the concept of semiotic interoperability (Li et al., 2013), which assesses interoperability from all six perspectives. We applied the semiotic 
interoperability in Healthcare Information Systems (HIS) (Liu et al., 2014) for proof of concept. In dealing with the interoperability issues at the pragmatic and social levels, as a guide to the assessment of interoperability we used organisation morphology (Liu, 2000), rooted in organisational semiotics, from other three perspectives: formal, informal and technical. The second research question at this stage was to establish the feasibility of evaluating semiotic interoperability among business processes from these three perspectives. To answer this question, a feasibility study was conducted in a hospital to prove our hypothesis and the results were used to develop a metrics for the measurement of interoperability.

The third phrase of the study examines the practicality of the metrics developed, and we propose a framework named the SIEF (Semiotic Interoperability Evaluation Framework) with a group of metrics for measuring interoperability from the semiotics perspective, applying the SIEF in a case study to validate its practicability.

This article is structured as follows: section 2 presents the background and theoretical foundation of the concept of semiotic interoperability. Section 3 discusses the research methods adopted by this study. Section 4 presents the findings of the feasibility study for the evaluation of interoperability among business processes. The findings indicate that interoperability evaluation among business processes can take place on three layers: the technical, the formal and the informal. The findings also identify the barriers to this evaluation, and the list is used as input in developing a metrics for the SIEF, as presented in section 5. Section 6 elaborates on the detailed metrics of the SIEF and gives measurements of the interoperability among business processes. Section 7 applies the SIEF in a case study, followed by analysis of the evaluation results. Section 8 critically discusses the case study from perspectives such as feasibility, applicability, consistency, accuracy and clarity. Both theoretical and practical contributions are emphasised, and the study's limitations and directions for future research are detailed in section 9.

\section{Background}

Interoperability is the ability of the entities of an organisation to work together, and it covers aspects ranging from technical to business concerns. Over the past decade, the interoperability concept and its context have changed rapidly. It has been extended from a largely IT-focused area to a business-focused issue (Froger et al., 2019; Škrinjar \& Trkman, 2013). Interoperability among information systems ensures that they can interact and thus achieve a shared objective (Dutot et al., 2014; Hu et al., 2017). The evaluation of interoperability is a growing concern in various research domains, and much research has contributed to this area. Many researchers have developed frameworks for the evaluation of interoperability, and our previous work (Liu et al., 2013, 2015, 2018) conducted a detailed comparative review of the existing approaches from six perspectives (physical, empirical, syntactic, semantic, pragmatic and social). The results reveal that most do not fully address the interoperability issues at the pragmatic level, at which an organisation's business processes, policies, behaviour and culture are 
considered. Therefore, we have proposed the concept of semiotic interoperability (Li et al., 2013), which assesses interoperability from all six perspectives.

\subsection{Definition of semiotic interoperability}

The concept of semiotic interoperability is based on the semiotic framework (Liu, 2000). This stems from organisation semiotics, which is a branch of the study of semiotics, and it provides both a sound theoretical foundation for understanding of the nature of the communication and a holistic view of the signs, information, systems and organisations involved (Stamper, 1973). Semiotic interoperability supports collaboration among business processes through understanding the intentions and social consequences. Table 1 describes the concept and its functional context at six constituent levels.

Physical interoperability enables seamless communication between the sender and receiver of a physical token that is transmitted via a route to the destination with no loss of physical properties. Empirical interoperability enables the receiver to reconstitute the same content, irrespective of any problems at the physical level. Syntactic interoperability indicates whether data structures and file formats are readable at both ends of the communication, so that information, language or formulae can be recognised by various collaborative information systems. Semantic interoperability ensures that the same meaning of the content is exchanged among the information systems. Specifically, this semantic interoperability not only entails the data being universally accessible and reusable but addresses the lack of common understanding caused by use of different semantic representations, such as dissimilar contexts or syntax-dependent approaches (Leal et al., 2017). Pragmatic interoperability ensures that the business processes supported by the information systems in each individual context can be aggregated to achieve the overall intended purpose. It permits the alignment of business workflows, processes and rules.

Table 1 Semiotic interoperability

\begin{tabular}{lll}
\hline & Definition & Functional context and relevant method \\
\hline Social & The resultant interoperable & - Alignment in traditions \\
level & digital systems should be & - Alignment in policies \\
& coherent with the social & - Alignment in culture \\
& commitments, obligations and & - Alignment in ethics \\
& norms in the organisation and & - Alignment in management style \\
& support its strategy, vision and & - Alignment in environment, etc. \\
& objectives & - Process reengineering \\
Pragmatic & Business processes supported by \\
level & the digital systems in their & - Process alignment \\
& individual contexts can be & - Rules modelling \\
& aggregated to achieve the overall & - Knowledge sharing \& knowledge repositories \\
intended purpose & - Business strategy alignment, etc.
\end{tabular}




\begin{tabular}{|c|c|c|}
\hline $\begin{array}{l}\text { Semantic } \\
\text { level }\end{array}$ & $\begin{array}{l}\text { Ability of interpreting and } \\
\text { converting information into } \\
\text { equivalent meaning to allow } \\
\text { information sharing among } \\
\text { digital systems }\end{array}$ & $\begin{array}{l}\text { - Semantic data representation } \\
\text { - Data standardisation } \\
\text { - Schema matching } \\
\text { - Ontology mapping } \\
\text { - Semantic matching, etc. }\end{array}$ \\
\hline $\begin{array}{l}\text { Syntactic } \\
\text { level }\end{array}$ & $\begin{array}{l}\text { Consistency between data } \\
\text { formats, structures and } \\
\text { programming languages } \\
\text { supporting data transmission }\end{array}$ & $\begin{array}{l}\text { - Data warehousing } \\
\text { - Data integration, e.g. ETL (Extract, Transform } \\
\text { and Load), EDI (Electronic data interchange) }\end{array}$ \\
\hline $\begin{array}{l}\text { Empirical } \\
\text { level }\end{array}$ & $\begin{array}{l}\text { Compatibility between channels } \\
\text { and protocols supporting data } \\
\text { transmission }\end{array}$ & $\begin{array}{l}\text { - Communication systems } \\
\text { - Messaging systems }\end{array}$ \\
\hline $\begin{array}{l}\text { Physical } \\
\text { level }\end{array}$ & $\begin{array}{l}\text { Connectivity between networks } \\
\text { and hardware and devices }\end{array}$ & $\begin{array}{l}\text { - Infrastructure standardisation } \\
\text { - EA (technology layer) and ITIL (Information } \\
\text { Technology Infrastructure Library) }\end{array}$ \\
\hline
\end{tabular}

Finally, social interoperability aligns the social aspects, such as culture, norms, environment and actors' behaviour patterns, to solve any conflicts of cohesiveness. Moreover, it ensures that the sender's intention or purpose leads to a social consequence for the receiver, which may be a social commitment, obligation or norm (Li et al., 2013). Social interoperability also ensures that these social consequences support the business strategy, vision, objectives and business environment (Saturno et al., 2017). There are various sub-areas under this topic, such as the alignment of traditions, policies, culture, ethics, management style and environment (Boonstra et al., 2011; Barbarito et al., 2012; Gregory et al., 2012; Liu et al., 2014). These cannot represent all the concerns and issues that social interoperability encompasses, because the topic is still under investigation and development.

\subsection{Evaluating the interoperability among business processes}

By comparatively analysing existing interoperability evaluation approaches, as mentioned, it has been established that most tackle interoperability issues only at the semantic, syntactic, empirical and physical levels; very few concentrate on evaluating it at the pragmatic and social levels (Liu et al., 2018). According to the definition of semiotic interoperability, pragmatic interoperability ensures that the business processes supported by information systems in individual contexts can be aggregated to achieve an overall intended purpose. Therefore, to evaluate semiotic interoperability at the pragmatic and social levels, as a guide to the assessment of interoperability we use organisation morphology (Liu, 2000), which is rooted in organisational semiotics, from three further perspectives: formal, informal and technical. As discussed previously, an organisation can be seen as an information system, because information is created and processed for the communication, coordination and achievement of an organisation's strategic goals (Liu, 2005). From an organisational perspective, information systems are defined by the cultural and legal norms that regulate people's behaviour (Liu, 2000). Thus, the definition 
of organisation is extended to a wider sense, such as a group of people, a society or a culture. An organisation does not only share languages, customs and habits but participates in the social construction of its own rules. In summary, an organisation may be regarded as an informal information system in which meanings are established, intentions understood, beliefs formed, commitments made and responsibilities negotiated through decisions on physical actions. The organisation morphology categorises these meanings, intentions, beliefs, commitments and responsibilities into three layers: the formal, the informal and the technical.

Business processes, on the formal layer, play a dominant role that drives business activity and operation, directly affecting business performance. However, studies of information systems have never treated them as sets of separate components but instead regarded them each as a whole, thus these business processes cannot be treated in isolation from aspects on the other two layers: the informal and the technical (Palmer et al., 2018). Thus, the business process also requires support from both these layers. According to Li's (2010) definition, a business process is a set of the activities that occur in a coordinated manner in pursuit of a single common goal. Looking at an entire information system, the activities are dynamic in nature yet have static aspects. The dynamic aspects include culture, norms and various behaviour patterns, while the static aspects include the technical system's capacity, data structure, data transmission, connections, and so on. Therefore, to evaluate the semiotic interoperability among business processes is to evaluate the interoperability on the formal, the informal and the technical layers. Table 2 describes the key aspects of each layer.

Table 2 Three layers for evaluating the interoperability among business processes

\begin{tabular}{ll}
\hline $\begin{array}{l}\text { Informal } \\
\text { layer }\end{array}$ & $\begin{array}{l}\text { Community, social norm, people, policy, culture, ethics, environment, alliances, } \\
\text { etc. }\end{array}$ \\
\hline $\begin{array}{l}\text { Formal } \\
\text { layer }\end{array}$ & $\begin{array}{l}\text { Organisational strategy/vision, business governance, domain analysis, organisational } \\
\text { roles, functional profile, rules, procedures, management, etc. }\end{array}$ \\
\hline $\begin{array}{l}\text { Technical } \\
\text { layer }\end{array}$ & $\begin{array}{l}\text { Data semantics, information infrastructure, information model, schema, script, interface, } \\
\text { platform, deployment model, resources, products, etc. }\end{array}$ \\
\hline
\end{tabular}

The informal layer consists of factors such as policy, social norms, community and culture. These factors can be expanded to various behaviour patterns. Interoperability on this layer depends on the coherence of each factor and the resolution of potential conflict that affects the collaborative strategy. On the formal layer, the business process plays dominant role and determines the functions and tasks. Interoperability at this layer depends on the alignment of procedures and rules to enhance the effectiveness and efficiency of the functions and tasks. It can be used to define the business goals, to model the business processes and ultimately to bring about collaboration by administrations that aim to exchange information among the various internal structures and processes. The technical layer mostly 
concerns technical computer systems and the implementation of their services, integration and functions. Interoperability at this layer depends on the alignment of technical functions and interfaces to ensure that, to achieve higher system productivity, this implementation has been performed properly.

Organisational morphology theory evaluates the interoperability among business processes on the three layers and is the foundation of the framework: the SIEF. It was necessary to investigate its feasibility before proposing the details of the SIEF. To do so, several cases of interoperability evaluation in industry were investigated. The findings of the feasibility study identified concerns and barriers on all the three layers, and these contribute to the SIEF's metrics.

\section{Method}

The essence of this study is that evaluating interoperability enables information-sharing among business processes, within which the meanings, boundaries and properties become understood. Studies of social meaning provide a better understanding of subjectivity with an epistemological stance than the objectivity adopted by the positivist and postpositivist paradigms (Liu, 2000). This study's research method has an underlying framework based on both prior theory and the results of a feasibility study, and it uses case study to test the constructs on which the framework was developed. As one of the most common qualitative methods in IS research, the case-study approach was chosen for its scope for intensive and in-depth analysis. One of its important advantages is the richness of the data collected, which renders them highly useful to the researcher to gain an understanding of complex phenomena (Yin, 2009).

The SIEF proposed in this article is a method for the assessment of interoperability among business processes. The Design Science Research guidelines were adopted, as these focus on developing artefacts with the explicit intention of improving performance (Hevner et al., 2004) and have been widely used for the evaluation of research projects. Moreover, Design Science is characterised by setting research goals, developing fundamental constructs for artifacts and carrying out an effective evaluation of the outcomes in line with its goals and validity (Venable, 2006).

This research used one case study to undertake a feasibility study before developing the SIEF, and one case study to evaluate the SIEF. The method adopted, developed by Seawright and Gerring (2008), matches the study's goal, case size and overall research design. Appropriate interviewees were selected on criteria such as their work experience and its technical relevance.

\subsection{Conducting the feasibility study}

The feasibility study was conducted by interviewing 31 experts in China at a healthcare software company and at the hospital for which it provides solutions. The company currently runs an integration project to share information between Electronic Health Records (EHR), Radiology Information Systems (RIS) and Picture Archiving and Communication Systems (PACS). At the hospital, the Radiology 
Department provides diagnostic and interventional radiology for inpatients, outpatients and general practitioner referrals. Various healthcare services, such as computed tomography (CT), X-ray and radiography (CR), produce a large amount of data on healthcare delivery and clinical processes. Relevant employees of the company and clinicians at the hospital were selected for interview.

The goal of the feasibility study was to investigate the grounds for proposing the SIEF, selecting appropriate cases following the guidelines developed by Seawright and Gerring (2008). The case is a medium-sized enterprise, which equates to approximately 200 employees working on various healthcare projects. This project involved 22 staff members at the company and nine clinicians at the hospital.

A screening process to select appropriate interviewees imposed several criteria. First was work experience: successful participants had to have more than three years of experience relating to software and systems development; if a clinician, they had to have this length of experience in directly using such information systems. Second was technical relevance: successful participants from the software company had to have been directly involved in the development of the project. Supporting roles were not accepted. The clinicians were treated as users of the software.

Following the imposition of these two criteria, 31 semi-structured interviews were conducted (as summarised in Table 3) on a one-to-one basis and lasting 20 to 30 minutes. All the interviews were audio recorded and later transcribed and rendered anonymous. The results are summarised in categories and presented in the following sections.

Table 3 Summary of feasibility study interviews

\begin{tabular}{lrrrcrrr}
\hline Sector & Sample & \multicolumn{9}{c}{ Years of experience } & & \\
& & $\mathbf{3}-\mathbf{5}$ & $\mathbf{6 - 1 0}$ & $\mathbf{1 1 - 1 5}$ & $\mathbf{1 6}-\mathbf{2 0}$ & $\mathbf{2 0 +}$ \\
\hline Industry & 22 & 7 & 11 & 2 & 1 & 1 \\
Hospital & 9 & 3 & 2 & 1 & 1 & 2 \\
\hline Total & 31 & 10 & 13 & 3 & 2 & 3 \\
\hline
\end{tabular}

Overall, 22 participants from industry were interviewed: seven at junior-manager level; 11 at seniormanager level (e.g. senior system architect, project manager); and four at executive level (e.g. CEO, CTO, director of software design or director of service delivery). Nine participants from the hospital were interviewed: four physicians; three radiology technicians; one IT manager with 11 years' experience; and one medical administration manager. The open interviews basically asked what concerns and barriers should not be ignored when assessing interoperability on three layers: the technical, the formal and the informal. The key results from the interview are given in section 4 .

The findings from the feasibility study were used to develop the SIEF's interoperability evaluation metrics. 


\subsection{Conducting the case study}

To validate the SIEF, a case study was conducted through interviews, a questionnaire and observations at a healthcare solution provider. To select an appropriate case, we agreed that the goal was to apply the SIEF to a healthcare company to evaluate the interoperability of its business processes. The case was again a medium-sized company, with approximately 150 employees spread between several departments. The study was carried out in the six departments mentioned in the case-study background.

To select appropriate interviewees, a screening process imposed several criteria. First was work experience: successful participants had to have had more than three years of experience. Second was technical relevance: successful participants had to have been directly involved in the development of the product. Supporting roles were not accepted. Details of the interviewees are summarised in Tables 6 and 7 , by experience and position, respectively.

Table 4 Summary of case study interviewees, by experience

\begin{tabular}{lrrrrrrr}
\hline Sector & Sample & \multicolumn{7}{c}{ Years of experience } & & \\
& & $\mathbf{3}-\mathbf{5}$ & $\mathbf{6 - 1 0}$ & $\mathbf{1 1 - 1 5}$ & $\mathbf{1 6}-\mathbf{2 0}$ & $\mathbf{2 0 +}$ \\
\hline Design \& Test Management & 8 & 4 & 2 & 1 & 1 & 0 \\
System Management & 10 & 5 & 2 & 0 & 3 & 0 \\
Product Management & 16 & 7 & 2 & 4 & 2 & 1 \\
Account Management & 5 & 2 & 2 & 1 & 0 & 0 \\
Supply Management & 10 & 4 & 2 & 2 & 1 & 1 \\
Service Management & 4 & 2 & 1 & 1 & 0 & 0 \\
\hline Total & 53 & 24 & 11 & 9 & 7 & 2 \\
\hline
\end{tabular}

Applying the two criteria, 53 semi-structured interviews were conducted on a one-to-one basis, lasting 30 to 40 minutes. All the interviews were audio recorded and later transcribed and rendered anonymous.

Table 5 Summary of case study interviewees, by position

\begin{tabular}{lrrrr}
\hline Sector & Sample & $\begin{array}{c}\text { Position } \\
\text { Junior }\end{array}$ & Senior & Director \\
\hline Design \& Test Management & 8 & 3 & 3 & 2 \\
System Management & 10 & 4 & 5 & 1 \\
Product Management & 16 & 7 & 6 & 3 \\
Account Management & 5 & 2 & 2 & 0 \\
Supply Management & 10 & 5 & 3 & 2 \\
Service Management & 4 & 3 & 1 & 0 \\
\hline Total & 53 & 24 & 20 & 8 \\
\hline
\end{tabular}


The timeline for collecting the data was as follows:

- $\quad$ Stage 1 - select appropriate case and derive questions from the SIEF (8 weeks)

- $\quad$ Stage 2 - choose participants for interview (7 weeks)

- $\quad$ Stage 3 - conduct interviews (14 weeks)

- Stage 4 - analyse results (10 weeks).

Some 53 participants from various departments completed the structured questionnaire. Some lacked the necessary knowledge of a particular assessment metric, thus were unable to answer the corresponding question, but overall they had to skip only approximately $5 \%$ of the survey questions.

It was important to evaluate the rigour involved in the application of the SIEF. An evaluation method developed by Lincoln and Guba (1985) was adopted, the criteria of which are: 1) clarity, to ensure that the language used to communicate is efficient and adequate for the audience; 2) accuracy, to ensure that there are no errors, so the results of the user actions correspond to their goals; and 3) effectiveness of the case study (Nielsen, 1994). The results of the evaluation are discussed in section 8.

4 Findings of the Feasibility Study

Through analysing the results of the feasibility study, we were able to identify the barriers that concerned most of the interviewees. They are summarised at three levels (informal, formal and technical) and are listed in Table 6, with details of each barrier. 
Table 6 Barriers at informal, formal, and technical layer

\begin{tabular}{|c|c|c|}
\hline Level & Barrier & Detail \\
\hline \multirow[t]{7}{*}{$\begin{array}{l}\text { Informal } \\
\text { level }\end{array}$} & Cultural issue & $\begin{array}{l}\text { Tacit knowledge has not been explicitly stated and } \\
\text { shared }\end{array}$ \\
\hline & Ethical issue & $\begin{array}{l}\text { Appropriateness of taking actions on healthcare service } \\
\text { delivery }\end{array}$ \\
\hline & Behavioural factor & Willingness to be open and to share \\
\hline & Management style & $\begin{array}{l}\text { Leadership style influencing the degree of willingness } \\
\text { of collaboration }\end{array}$ \\
\hline & Policy and procedure & $\begin{array}{l}\text { Internal control process, workflow, staff relationships, } \\
\text { communication patterns, cut across political boundaries, } \\
\text { etc. }\end{array}$ \\
\hline & $\begin{array}{l}\text { Restriction on staff } \\
\text { behaviour }\end{array}$ & $\begin{array}{l}\text { Staff's fear on integrated working process as restriction } \\
\text { that might control their behaviour }\end{array}$ \\
\hline & Privacy and security & Sensitive information of patient to be protected by law \\
\hline \multirow{7}{*}{$\begin{array}{l}\text { Formal } \\
\text { level }\end{array}$} & $\begin{array}{l}\text { Organisational } \\
\text { structure }\end{array}$ & $\begin{array}{l}\text { Centralised, decentralised, hierarchical, matrix, } \\
\text { networked, etc. }\end{array}$ \\
\hline & Harmonised strategy & $\begin{array}{l}\text { Aligned operations to be applicable on the strategic } \\
\text { level }\end{array}$ \\
\hline & $\begin{array}{l}\text { Performance } \\
\text { constraints }\end{array}$ & Fewer investment but more effective collaboration \\
\hline & Cost constraints & Unexpected budget \\
\hline & $\begin{array}{l}\text { Data source } \\
\text { interoperability }\end{array}$ & Multiple data sources used for supporting process \\
\hline & Context awareness & $\begin{array}{l}\text { Knowledge of context of both collaborative } \\
\text { parties/processes }\end{array}$ \\
\hline & $\begin{array}{l}\text { Varieties of } \\
\text { purchased systems }\end{array}$ & $\begin{array}{l}\text { Purchased systems from various venders with low } \\
\text { capability }\end{array}$ \\
\hline \multirow{6}{*}{$\begin{array}{l}\text { Technical } \\
\text { level }\end{array}$} & $\begin{array}{l}\text { Semantic } \\
\text { heterogeneity }\end{array}$ & $\begin{array}{l}\text { Refers to the variation of semantic meaning in } \\
\text { information resources which will lead to the semantic } \\
\text { conflict and complication for data integration }\end{array}$ \\
\hline & Ontological structure & $\begin{array}{l}\text { Approaches that employ ontologies for information } \\
\text { systems }\end{array}$ \\
\hline & Business semantics & Defining ontology and semantic conversion \\
\hline & $\begin{array}{l}\text { Ambiguous } \\
\text { terminology }\end{array}$ & Differences in the use of terms across departments \\
\hline & $\begin{array}{l}\text { Implementation of } \\
\text { data integration }\end{array}$ & $\begin{array}{l}\text { Defining source and target data format; data } \\
\text { transformation and mapping; deploy on execution } \\
\text { infrastructure }\end{array}$ \\
\hline & $\begin{array}{l}\text { Implementation of } \\
\text { service integration }\end{array}$ & $\begin{array}{l}\text { Services for connecting processes and message } \\
\text { exchange }\end{array}$ \\
\hline
\end{tabular}


The technical level is fundamental to the exchange of data among business processes. For example, in a healthcare environment the technical level is concerned with understanding the technical functionality to support communication among the various information systems. Especially from a project management perspective, both data and service integration should already have been successfully implemented. This is to ensure that the source and target data formats are consistent, the services for connecting processes are articulated and that there is a robust network infrastructure. To achieve the technical level, agreement is required on a core set of technical concepts, for instance the technical devices, the interactions between them, the interfaces and the technical services. Furthermore, the business semantics and any ambiguous terminologies used across departments should be clarified, and this involves eliminating all semantic conflict, such as variations in meaning in information resources. As many studies have addressed these issues already, the evaluation of interoperability at a technical level is not the focus of this article.

To assess interoperability at the formal level, the exchange of information among technical systems is not the only concern: more decisive is knowledge of the context within each system or process. As one IT project manager in the interview stated:

It is important to articulate the requirement for context awareness that process representation begins. The context of the target system should also be made available to the origin system. Key questions such as what process will first operate on the information at the target system once it receives it should be concerned...

By understanding this context, a system architect is able to comprehend the pragmatic interoperability and can meet the requirements of process integration. To define the context, one manager in the logistics department stated:

the context is about internal workings of the process, in other words, the initialization state, the end state, the nature of data transformations, and details about the timing of the process are all considered, so that the receiving process can make better use of information it receives.

This information is in context, and it also reveals the dynamic nature of the originating system to the receiving system, which now has specific information about this context. Therefore, to avoid potential conflict, knowledge of the context of both collaborative processes should be completely interpreted. Besides context awareness, it is necessary for the organisational structure to be consistent to ensure that operations are aligned at all levels, especially the strategic level. Other constraints at the formal level, such as underperformance and unanticipated costs, have a minor impact on interoperability and can be resolved by a more efficient management system.

Interoperability at the informal level rests on the alignment of understandings of the regulatory and legislative healthcare environment in which particular processes to support healthcare delivery take place. It requires agreement on all key concepts, such as policies, regulations and processes, so that the interoperability can capture relevant patterns for governance, compliance and change management. 
Sharing the intended purpose is the key criterion of interoperability. This supports the perception of intangibles, such as personal beliefs and the ground rules in the working environment, to permit collaboration among business processes. In a collaborative context, any failure to share the purpose may result in considerable conflict of coherence. There are several potential issues, such as restrictions on staff behaviour, privacy and security concerns. In some countries patient information is strictly protected by healthcare organisations, and the feasibility study revealed that many staff are unwilling to share information across departments. This reluctance to be open is influenced by management style, and some department managers indeed encourage collaborative initiatives and facilitate workshops and fora for the exchange of insights. These managers suggest that healthcare organisations should devise policies to formalise such collaborative initiatives, setting out internal control processes, workflows and communication patterns that help to cut across political boundaries between departments. However, the majority of junior staff members object to this suggestion, as they question whether the integrated working processes might restrict their behaviour and double their workload. In addition, although they were unwilling to elaborate, many interviewees stated that culture and ethical issues have an impact on the appropriateness of taking action on healthcare service delivery.

\section{The Semiotic Interoperability Evaluation Framework}

Based on the findings of the feasibility study, the SIEF was developed with a set of supporting metrics derived from the barriers that were identified (Table 5). The framework groups metrics into three categories, but there are no explicit boundaries between the three as we do not treat interoperability assessment as at separate levels but regard them as a whole, in the same way as we see information systems. All three levels of the SIEF are concerned with the pragmatic and social levels of the semiotic framework. If there must be boundaries, then the two groups of technical and formal metrics and that of the informal metrics could match the pragmatic and social levels, respectively, with overlapping metrics. A detailed explanation of each metrics is provided in Appendix II. 
Table 7 The Semiotic Interoperability Evaluation Framework (the SIEF)

\begin{tabular}{|c|c|c|}
\hline Technical metric & Formal metric (performance measure) & Informal metric (indicator) \\
\hline \multirow{2}{*}{$\begin{array}{l}\text { Modelling business } \\
\text { document }\end{array}$} & Business strategy & \multirow{4}{*}{ Tradition and culture } \\
\hline & Clarity in strategic goals & \\
\hline High-level model & $\begin{array}{l}\text { Formal commitment to prevent termination } \\
\text { or premature collaboration }\end{array}$ & \\
\hline Components model & Backup strategic plan & \\
\hline $\begin{array}{l}\text { Implementation of } \\
\text { data integration }\end{array}$ & Management of external relationships & \multirow[t]{2}{*}{ Management style } \\
\hline Source and target & Partner selection & \\
\hline $\begin{array}{l}\text { data format } \\
\text { definition }\end{array}$ & $\begin{array}{l}\text { Partner assessment } \\
\text { Operation contracts }\end{array}$ & Religion \\
\hline $\begin{array}{l}\text { Data mapping and } \\
\text { transformation }\end{array}$ & $\begin{array}{l}\text { Conflict resolution } \\
\text { Communication }\end{array}$ & $\begin{array}{l}\text { Appropriateness of taking } \\
\text { actions }\end{array}$ \\
\hline $\begin{array}{l}\text { Implementation of } \\
\text { service integration }\end{array}$ & $\begin{array}{l}\text { Collaborative business processes } \\
\text { management }\end{array}$ & Employee's motivation \\
\hline Deployment on & Clarity in responsibility & \multirow{3}{*}{ Employee's honesty } \\
\hline $\begin{array}{l}\text { execution } \\
\text { infrastructure }\end{array}$ & Business process modelling & \\
\hline Services for & Clarity in business process & \\
\hline connecting processes & Process visibility & \multirow{3}{*}{ Resistance to change } \\
\hline \multirow{2}{*}{$\begin{array}{l}\text { Services for message } \\
\text { exchange }\end{array}$} & $\begin{array}{l}\text { Intellectual property rights (IPR) } \\
\text { management }\end{array}$ & \\
\hline & IPR protection & \\
\hline Business semantics & $\begin{array}{l}\text { Potential IPR } \\
\text { IPR conflict }\end{array}$ & \multirow{3}{*}{$\begin{array}{l}\text { Fear of behaviour control by } \\
\text { others }\end{array}$} \\
\hline $\begin{array}{l}\text { Ontological } \\
\text { definition }\end{array}$ & Organisational structure & \\
\hline Semantic conversion & Role mapping & \\
\hline
\end{tabular}

To evaluate the interoperability between two business processes, the SIEF will assess each metric at all three levels, ensuring that their technical metrics are matched, their performance measures are in accordance and their informal indicators are in line. Figure 1 illustrates how the interoperability evaluation is conducted, showing the breakdown between the two business processes. 


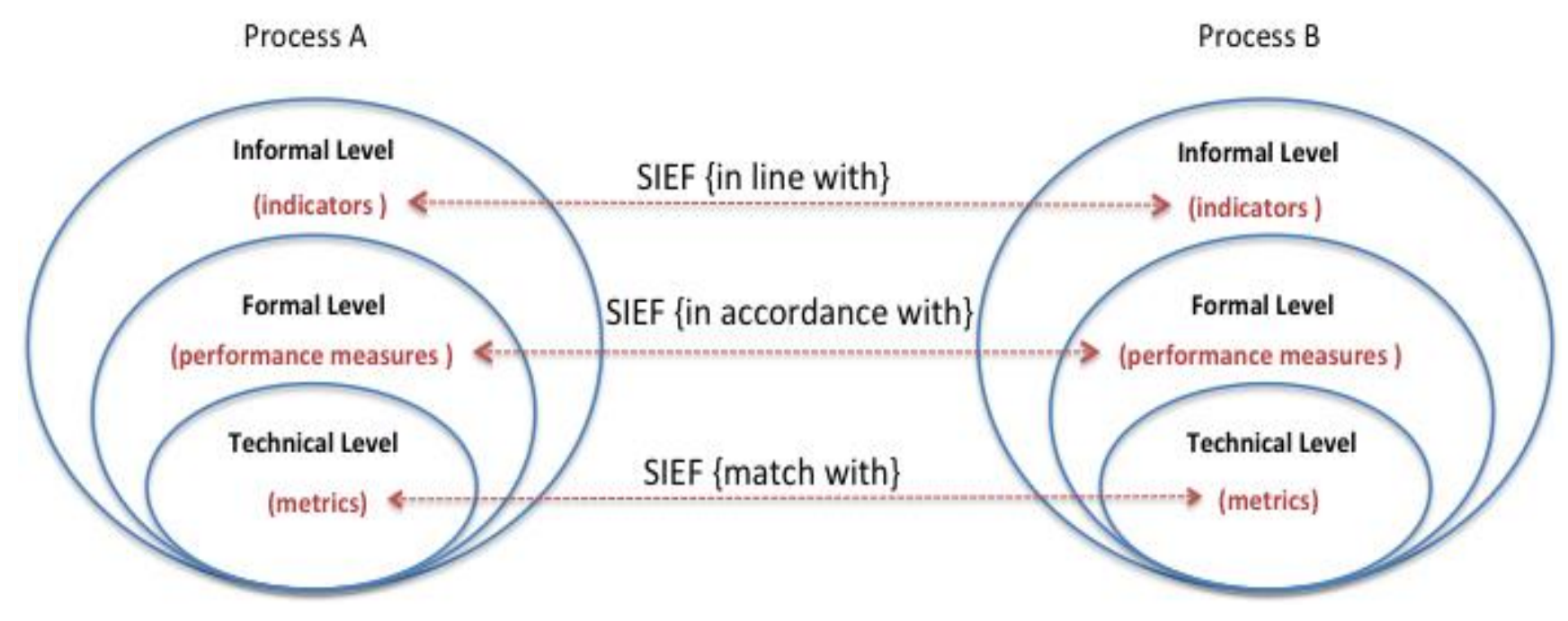

Fig.1 Evaluation of semiotic interoperability

The interoperability between Process A and Process B is the sum of the interoperability at each of the three levels, and it can be presented as Equation 1:

$\mathrm{I}\left(\mathrm{P}_{\mathrm{a}}, \mathrm{P}_{\mathrm{b}}\right)=\mathrm{I}_{\mathrm{Te}}\left(\mathrm{P}_{\mathrm{a}}, \mathrm{P}_{\mathrm{b}}\right)+\mathrm{I}_{\mathrm{Fo}}\left(\mathrm{P}_{\mathrm{a}}, \mathrm{P}_{\mathrm{b}}\right)+\mathrm{I}_{\mathrm{In}}\left(\mathrm{P}_{\mathrm{a}}, \mathrm{P}_{\mathrm{b}}\right)$

where

$\mathrm{I}\left(\mathrm{P}_{\mathrm{a}}, \mathrm{P}_{\mathrm{b}}\right)$ : Interoperability between two processes, $\mathrm{A}$ and $\mathrm{B}$;

$\mathrm{I}_{\mathrm{Te}}\left(\mathrm{P}_{\mathrm{a}}, \mathrm{P}_{\mathrm{b}}\right)$ : Interoperability at the technical level;

$\mathrm{I}_{\mathrm{Fo}}\left(\mathrm{P}_{\mathrm{a}}, \mathrm{P}_{\mathrm{b}}\right)$ : Interoperability at the formal level;

$\mathrm{I}_{\mathrm{In}}\left(\mathrm{P}_{\mathrm{a}}, \mathrm{P}_{\mathrm{b}}\right)$ : Interoperability at the informal level.

At the informal level, the metrics are termed indicators, which means the indicators of Process A such as its management style, religion, appropriateness of taking actions, employee motivation and employee honesty, and that these should be in line with the indicators of Process B. At the formal level, the metrics are termed performance measures, which are the measures of Process A such as its clarity in business strategy, backup strategic plan, management of external relationships and clarity in responsibility, and these measures should be in accordance with the performance measures of Process B. At the technical level, the metrics of Process A such as its design of services, its model of business document and its implementation of data/service integration should match the metrics of Process B.

The metrics presented above are used as the foundation for the evaluation of interoperability among business processes. To assess all the metrics, they were transformed into a questionnaire. The solutions/methods/tools to address each metric were the key criteria for whether the concern of the metric was addressed or not. For example, in measuring the metrics of business semantics, the 
technology OWL-S and similar technologies were used to check whether the organisation had implemented such technologies to deal with the concern. More details of measuring and scoring method are presented in the following section.

\section{Measuring the Interoperability Among Business Processes}

To measure the interoperability of the metrics, each was transformed into a questionnaire and the solutions/methods/tools to address it became the key criteria for whether its concern had been addressed or not. Each was allocated a score from 1 (strongly disagree) to 5 (strongly agree), and a pondering coefficient $\alpha_{\mathrm{i}} \in[0,1]$, which determines the importance of its effect. For example, to measure Highlevel model of business document, participants were asked to rate the use of tools and solutions (e.g. Maestro, XML Editing Tools) for modelling a high level of business documents to help to gain a better understanding of solving interoperability issues during collaboration. If these tools and solutions mentioned were not used by the participant yet there were alternatives, the participant was to give details of these tools and rate them accordingly. The participant's response to the question (1-5) is the assessment score $\mathrm{TS}_{\mathrm{i}} \in[0,4]$, with a corresponding pondering coefficient of the metric. The standard deviation (Std) is given to identify the variation in responses to each single metric.

By applying the single-metric assessment method to interoperability Equation 1, the result of interoperability assessment between Process A and Process $\mathrm{B}, \mathrm{I}\left(\mathrm{P}_{\mathrm{a}}, \mathrm{P}_{\mathrm{b}}\right)$ is the combination of the scores of interoperability at the technical, $\mathrm{I}_{\mathrm{Te}}\left(\mathrm{P}_{\mathrm{a}}, \mathrm{P}_{\mathrm{b}}\right)$, formal, $\mathrm{I}_{\mathrm{Fo}}\left(\mathrm{P}_{\mathrm{a}}, \mathrm{P}_{\mathrm{b}}\right)$ and the informal levels, $\mathrm{I}_{\mathrm{In}}\left(\mathrm{P}_{\mathrm{a}}, \mathrm{P}_{\mathrm{b}}\right)$, as illustrated by Equation 2:

$$
\mathrm{I}\left(\mathrm{P}_{\mathrm{a}}, \mathrm{P}_{\mathrm{b}}\right)=\sum_{i=1}^{n(T)} \alpha_{i} * T S_{i}+\sum_{i=1}^{n(F)} \delta_{i} * F S_{i}+\sum_{i=1}^{n(M)} \beta_{i} * M S_{i} \mid \alpha_{\mathrm{i}}, \delta_{\mathrm{i}}, \beta_{\mathrm{i}} \in[0,1] ; \mathrm{TS}_{\mathrm{i}}, \mathrm{FS}_{\mathrm{i}}, \mathrm{MS}_{\mathrm{i}} \in[0,4]
$$

where

$\mathrm{I}\left(\mathrm{P}_{\mathrm{a}}, \mathrm{P}_{\mathrm{b}}\right)$ : Overall interoperability score between business processes $\mathrm{A}$ and $\mathrm{B}$

$\mathrm{I}_{\mathrm{Te}}, \mathrm{I}_{\mathrm{Fo}}, \mathrm{I}_{\mathrm{In}}$ : Interoperability at the technical, formal and informal levels, respectively

$\alpha_{\mathrm{i}}, \delta_{\mathrm{i}}, \beta_{\mathrm{i}}$ : pondering coefficient at the technical, formal and informal levels, respectively

$\mathrm{TS}_{\mathrm{i}}, \mathrm{FS}_{\mathrm{i}}, \mathrm{MS}_{\mathrm{i}}$ : Assessment score at the technical, formal and informal levels, respectively

$\mathrm{n}(\mathrm{T}), \mathrm{n}(\mathrm{F}), \mathrm{n}(\mathrm{M})$ : Number of metrics at the technical, formal and informal levels, respectively.

The use of a questionnaire to assess interoperability has been widely adopted by researchers. Cornu et al. (2012) propose one at highly technical level for the assessment of interoperability among organisational units, while Palomares et al.'s (2010) method for developing a questionnaire to assess interoperability emphasises several domains. The LISI (Level of Information Systems Interoperability), one of the few studies to use the concept of interoperability, employs a questionnaire but only at the 
level of data connection. Rather than other interoperability evaluation approaches, the sector tends to have accepted the questionnaire due to its simplicity and researchers' experience in using it. Besides, the SIEF can construct groups of questions to focus on separate domains, making it possible to optimise the performance of its analysis, especially in coping with future change.

7 SIEF Case Study: Evaluating the interoperability among business processes

The case study was conducted through interviews, a questionnaire and observations at a medium-sized healthcare solution provider. It focused on instant communication among care staff members via voice, video and text messages through the hospital's communication system, which is integrated with its electronic health records, alarms and nurse-call systems. The entire design and production process had taken nearly 18 months and represented a tremendous effort to collaborate with all the teams and departments, and the product had been released recently.

The case-study participant observation was carried out during the product development process, and two business processes (i.e. new product development (NPD) and deliver to order (DTO)) were examined to assess the interoperability between them. Stakeholders (e.g. project managers and engineers) participated in both interviews and the questionnaire.

The NPD process involved three departments: Design \& Test Management; System Management; and Product Management. First, the Product Management team defined the business and product needs, then passed the results to the System Management team to specify the product. Meanwhile, the Product Management team had estimated the market offer for the product and discussed it with another department - Account Management - that had not yet been involved in the NPD process. Once the specification of the product had been confirmed, the Design \& Test Management team took over the product design and verification. The completed product design was sent back to the Product Development Management team for deployment after manufacture in a subcontracted factory. The product was released when confirmation had been received from the other business process, DTO.

The DTO process involved three departments: Account Management; Supply Management; and Service Management. The Account Management team was in charge of creating the business account and forecasting sales for the product's business evaluation. The Supply Management team focused on logistics management, while the Service Management team implemented solutions and provided service support for logistics.

Figure 2 illustrates the two business processes, including the departments involved. 
Process A:

New Product Development (NPD)
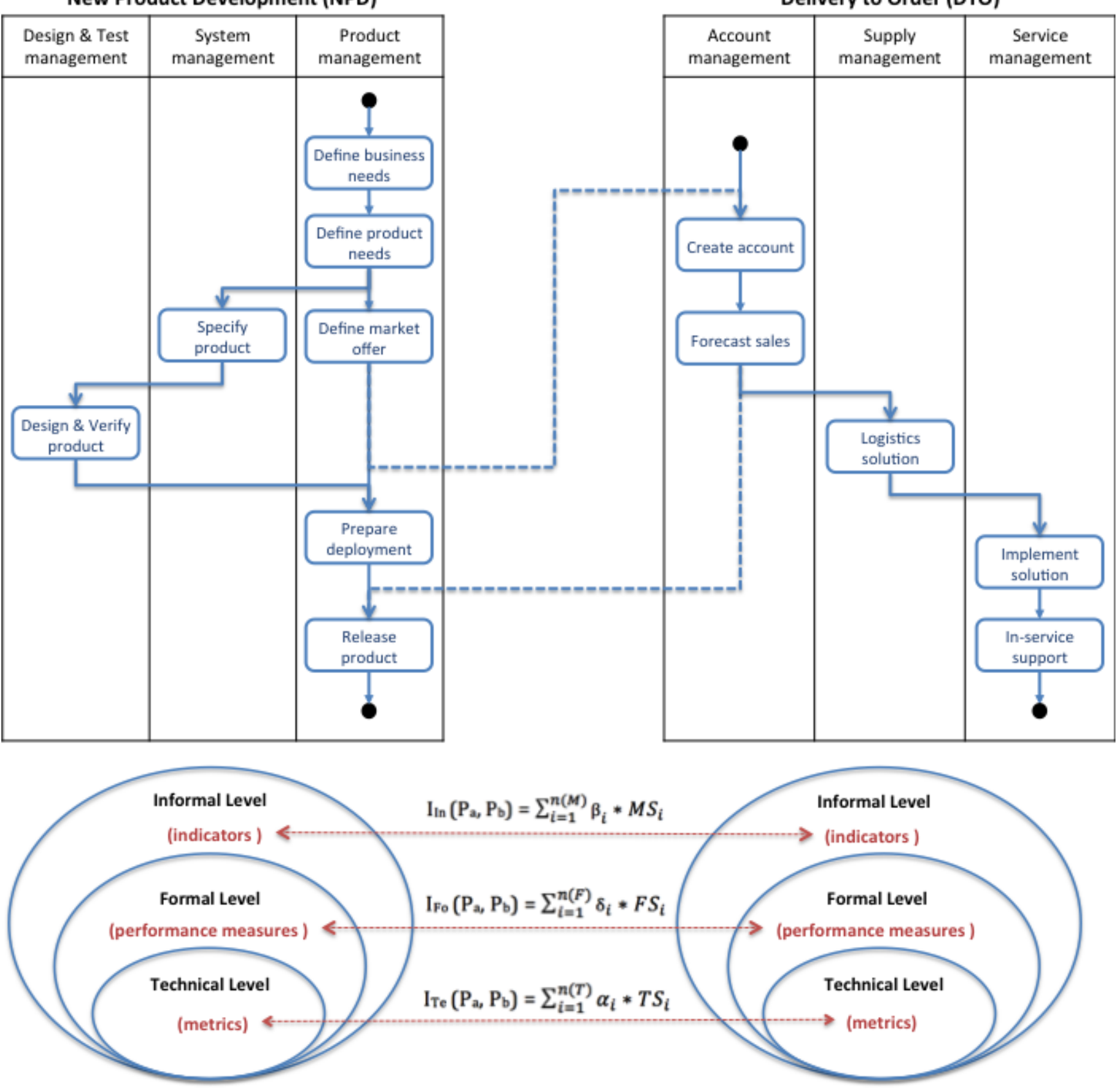

Fig.2 Interoperability between two business processes

The results of the assessment (score) for interoperability between the NPD and the DTO processes are summarised at three levels, and detailed results are presented in Appendix I. The interviewees were asked questions derived from the metrics. They allocated each a score from 1 (strongly disagree) to 5 (strongly agree), according to how well the corresponding solution or tools had been used to improve the interoperability. In addition, the participants allocated a pondering coefficient $\alpha_{\mathrm{i}} \in[0,1]$ to each metric. The standard deviation (Std) identifies the variation in response to each single metric. Tables 8 to 10 in Appendix I give the interoperability score for each metric at the technical, formal and informal levels. 
In summary, the overall interoperability scores at the three levels are:

Technical level: $\mathrm{I}_{\mathrm{Te}}\left(\mathrm{P}_{\mathrm{a}}, \mathrm{P}_{\mathrm{b}}\right)=\sum_{i=1}^{n(T)} \alpha_{i} * T S_{i}=28.99$

Formal level: $\mathrm{I}_{\mathrm{Fo}}\left(\mathrm{P}_{\mathrm{a}}, \mathrm{P}_{\mathrm{b}}\right)=\sum_{i=1}^{n(F)} \delta_{i} * F S_{i}=39.21$

Informal level: $\mathrm{I}_{\mathrm{In}}\left(\mathrm{P}_{\mathrm{a}}, \mathrm{P}_{\mathrm{b}}\right)=\sum_{i=1}^{n(M)} \beta_{i} * M S_{i}=13.13$

The interoperability scores from the NPD process perspectives are:

Technical level: $\mathrm{I}_{\mathrm{Te}}\left(\mathrm{P}_{\mathrm{a}}, \mathrm{P}_{\mathrm{b}}\right)=\sum_{i=1}^{n(T)} \alpha_{i} * T S_{i}=32.41$

Formal level: $\mathrm{I}_{\mathrm{Fo}}\left(\mathrm{P}_{\mathrm{a}}, \mathrm{P}_{\mathrm{b}}\right)=\sum_{i=1}^{n(F)} \delta_{i} * F S_{i}=39.89$

Informal level: $\mathrm{I}_{\mathrm{In}}\left(\mathrm{P}_{\mathrm{a}}, \mathrm{P}_{\mathrm{b}}\right)=\sum_{i=1}^{n(M)} \beta_{i} * M S_{i}=14.42$

The interoperability scores from the DTO process perspectives are:

Technical level: $\mathrm{I}_{\mathrm{Te}}\left(\mathrm{P}_{\mathrm{a}}, \mathrm{P}_{\mathrm{b}}\right)=\sum_{i=1}^{n(T)} \alpha_{i} * T S_{i}=26.51$

Formal level: $\mathrm{I}_{\mathrm{Fo}}\left(\mathrm{P}_{\mathrm{a}}, \mathrm{P}_{\mathrm{b}}\right)=\sum_{i=1}^{n(F)} \delta_{i} * F S_{i}=38.71$

Informal level: $\mathrm{I}_{\mathrm{In}}\left(\mathrm{P}_{\mathrm{a}}, \mathrm{P}_{\mathrm{b}}\right)=\sum_{i=1}^{n(M)} \beta_{i} * M S_{i}=12.03$

The case study shows that there is no doubt that companies are becoming more ICT interconnected and dependent on each other. The technical element is no longer the only decisive element for interoperability assessment among business processes. Other elements, such as metrics at formal level (the management of external relationships, business semantics and intellectual property rights (IPR) policy), should also be considered. Semantics is a well-known challenge in interoperability that researchers have been attempting to overcome for decades. While semantics is more related to ease of information processing, the security of protected information and IPR is increasingly a social issue, particularly in design-valued businesses, and represents a serious hindrance to the attainment of higher levels of interoperability. The interpretation of the measured metrics is difficult, as it partly depends on 
the type, complexity and scope of organisational functions, operations and processes. Some experts are in consensus over the measures, but others have differing views. We can observe this in the value of the standard deviation. In order to analyse the data more objectively, we present the results from two perspectives (NPD and DTO). Looking at the results separately in this way, the difference in results for some metrics is significant. Figures 3, 4 and 5 present comparisons of the assessment results at the technical, formal and informal levels.

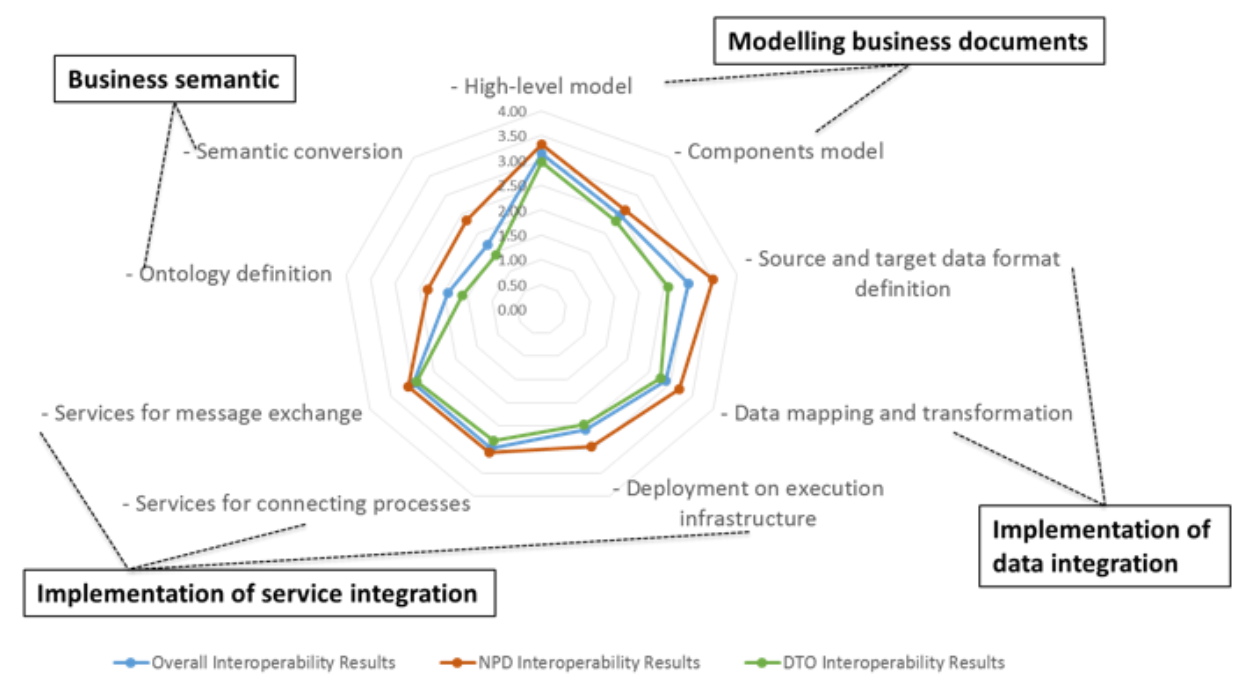

Fig.3 Comparison of results of interoperability assessment at the technical level

At the technical level, the NPD participants scored every metric higher than the DTO participants. The differences in response to semantic conversion, data format consistency, service definition and interface are quite significant. Semantics addresses the issue of defining a common terminology for the information to be exchanged among the business processes. According to the results, although standardisation initiatives produce data dictionaries and information models, in this case a comparable level of shared semantics is still lacking. From the NPD perspective, the focus is on the terminology and meaning of the information to be exchanged as well as on the data structure to be implemented in the systems.

Since the NPD process involves the Design \& Test, Systems Management, and Product Management departments, more IT architects, engineers and experts are involved in defining a common ontology. However, the DTO process includes the Account Management, Supply Management and Service Management departments, in which a shared database has not been fully implemented. Moreover, the system used by the Service Management department is provided by another supplier, independent from the rest. Unlike the significant difference in metrics, for instance the semantics and the data integration implementation, the assessment results of the high-level model and the components models are very similar. Both models contain business documents, forming the basis of the data and service integration. In this case study, IT architects created the models with tools for service specification (XMLSpy) and XML editing tools for mapping business documents, and these were applied in all departments. 
The assessment results at the technical level provided the project manager only with oversight that the necessary technical tools were employed to support the collaboration. However, at the formal and informal levels, the assessment results are able to indicate the effectiveness of the collaboration.

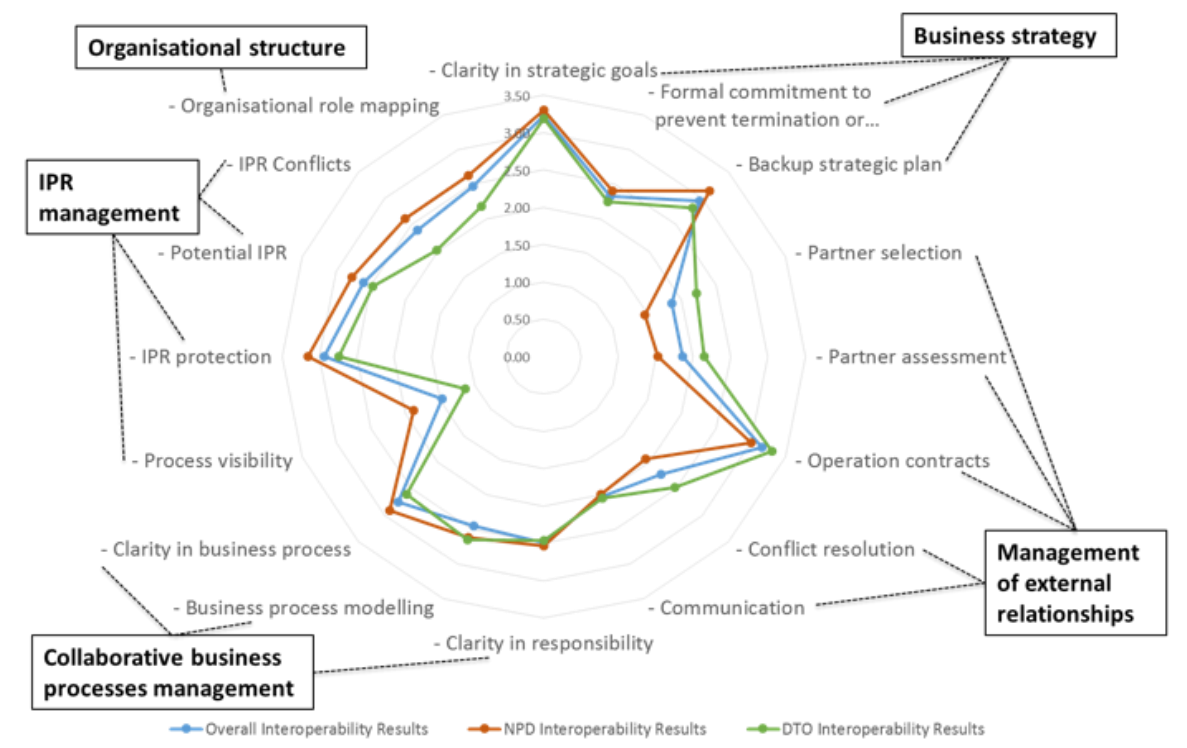

Fig.4 Comparison of results of the interoperability assessment at the formal level

From the NPD perspective, the assessment scores are higher for the metrics of Business Strategy, Business Process Management and IPR Management. The stakeholders in the NPD process were quite clear about their strategy goals for business strategy, especially regarding the product's functions, competitive advantages and provided services. However, while the stakeholders in the DTO process did not know the details of the product, they were familiar with the supplements to the product development, for instance the estimated cost and component supply. Both provided backup plans for preventing failure in product development and supply management, but had not committed to each other to prevent termination of the collaboration. In IPR management, from the NPD perspective the assessment results of IPR protection, solving conflict and establishing potential IPR were slightly higher, as these are deeply concerned with the product development perspective to avoid the potential risk of infringement.

By contrast, the DTO process concentrates on the Management of External Relationships, including partner selection and assessment and conflict resolution, yet the results show that the NPD stakeholders are not quite satisfied with the partners selected. As stated by one of the product managers:

We sometimes face the problem that some components provided by our supplier do not $100 \%$ fit our requirements, and more frustratingly, we cannot identify the problem such as incompatibility, components breakdown until we have embedded them in, which may be caused by inexplicit specification we requested, and more importantly, the quality of the components. I admit this is sometimes due to the lack of proper communication between our engineers and supply management department, but I believe this could be certainly avoided if the partner assessment procedure is improved... 
Furthermore, an interesting point is that the assessment score for process visibility is significantly lower than that of the others. This is not just the assessment score: the pondering coefficient is also very low, because most participants do not think that their own workflow and procedures need to be visible to others. The assessment score is slightly better from the NPD perspective, as the departments involved require closer cooperation to achieve product development. For example, participants from System Management and Design \& Test Management scored a higher pondering coefficient, indicating that they would like to make their workflow transparent to each other.

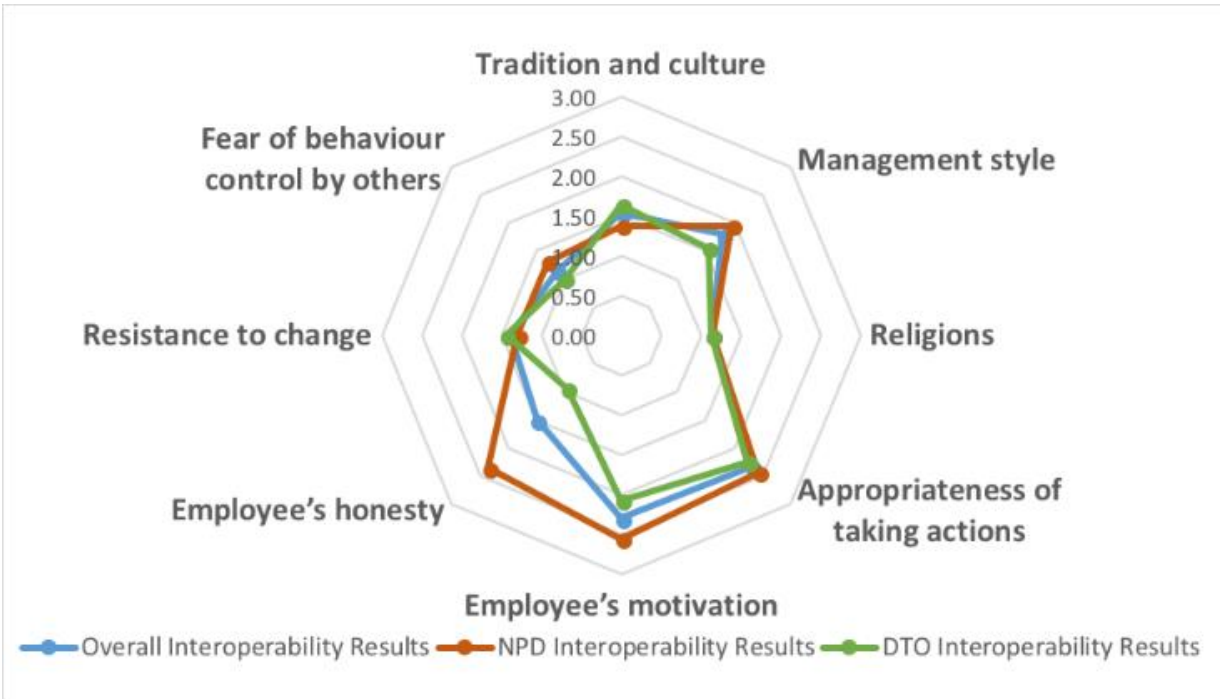

Fig.5 Comparison of results of the interoperability assessment at the informal level

Collaboration among business processes yields a change in management, and it is important to align the working culture in a collaborative environment when dealing with issues such as failure tolerance, resistance to change, adaptations to the management style and openness in dealing with potential or specific problems (Zutshi et al., 2012). By looking at the comparison of results, it seems that from the NPD perspective there should be a better method to resolve employees' fear that their behaviour is controlled by others. Further, NPD participants seem to be more adaptable to the change in management style. The differences in tradition, culture and religion are not significant, as the case study was conducted in China, where employees do not feel strongly the cultural differences in the workplace and the range of religions does not much affect the working environment, mainly. One interesting point is that stakeholders in the NPD process believe that an employee's honesty is important to collaboration, because in the technology-based product development sector, where rapid innovation takes place, product information is highly sensitive for all the stakeholders. Information security is highly reliant on employee honesty, besides non-disclosure agreements. As stated by a product manager:

the competition in this industry is fierce, the threshold for entering this market becomes lower and lower, and there is an increasing number of companies joining and developing similar products every single month. From the functionality perspective, we no longer have competitive advantages as other products can do exactly what we do. 
Thus, our emphasis has been moving towards improving user experience, on one hand, and service innovation on the other. That is where employees' honesty should be concerned, and we appreciate that if sensitive information is not even shared within departments....

Moreover, looking at the standard of deviation for employee motivation and resistance to change, both were allocated quite a high pondering coefficient by NPD participants. This is because, as stated by a project manager ,'the product innovation is the core drive...' and 'motivating the teams involved in new product development has been our focus all the time...'.

\section{Discussion}

An interoperability evaluation framework should be able to define the technical standards, organisation policies, behaviour patterns and information specifications. These support interconnection and exchange among separate business processes and allow systems to work together (Koens \& Poll, 2019). An interoperability evaluation framework should also provide the shared vision and strategies for coordinating changes in order to support complex interactions among business processes (Bouloukakis et al., 2019). An appropriate interoperability evaluation guide, together with engagement with all metrics, is critical to success.

Our previous state-of-the-art analysis of existing interoperability evaluation frameworks revealed that most approaches do not fully address interoperability issues at the pragmatic level, which considers an organisation's business processes, policies, behaviour and culture. Hence, the SIEF was developed to assess interoperability at all levels, as research efforts have usually developed guidelines and standards for just the technical, syntactic and semantic levels (Hu et al., 2017). The case study conducted was based on both open-ended interviews with the organisation's top management and the advice of experts in the domains of interoperability, systems integration and process alignment. Data collected from various sources were analysed through expert interviews and discussions and the interpretation of a semi-structured survey.

\subsection{Recommendations}

In terms of the applicability of the SIEF, including its metrics, one issue concerns the entire evaluation process: the cost constraints. As both the interview and the questionnaire were relevant to the research, the assessment consumed too many resources to obtain in-depth insights into some aspects. Bannister (2007) argues that measurement methodologies are guided by cost constraints:

Often data is collected using limited funds resulting in incomplete investigations where outcomes might not be true or may only cover the situation partly. It is, however, questionable if it is desired or feasible to have hundreds of questions for measuring all the details about the measures.

This would result in huge information overload, a waste of resources and confusion. Therefore, it is 
reasonable for a limited number of questions to be answered within a short time frame. The structured questionnaire in this study includes approximately 30 questions and its focus is on the assessment of the interoperability of the business processes rather than that of highly technical matters, thus avoiding unnecessary usage of resources. However, we would agree that there is scope to achieve even more conciseness in the questionnaire.

Further metrics are recommended for addition to the framework, for instance human resources, change management and financial constraints (Leal et al., 2017). These are also important in the evaluation of interoperability, as they constitute the basis for employees' enhanced interaction, collaboration and workflow. Besides, if the human resources are inadequately skilled and trained, technology alone cannot resolve the interoperability problems of business processes.

Policy is often developed by management in a top-down approach, without consulting the operational staff. Including policy aspects in the assessment can allow employees to reflect, participate and advise in the policy-making process (Saturno et al., 2017). However, involving a large proportion of the workforce in collecting data and identifying improvement suggestions is cumbersome, as the data might be biased. Thus, it is best to ensure beforehand that they are able to interpret the data, understand the internal functioning and acquire knowledge on the metrics (Kasunic \& Anderson, 2004). To meet this requirement, the open-ended interviews conducted for the case study not only provided in-depth questions but offered a better understanding of the underlying information on the organisation's operations, interactions and collaborations. As a result, the case study recursively supports, updates and improves the structured questionnaire. Though the participants were aware of the procedure, participative observation was necessary to confirm the findings of the interviews and questionnaires. Furthermore, this observation prompted immediate reflections and discussions on the applicability and usefulness of the assessment metrics.

Social network interoperability may be a further aspect to be added to the SIEF. This refers to the ability of organisations to seamlessly interconnect and utilise social networks for collaboration purposes (Abel et al., 2009), and can be done by aligning the organisation's internal structure to the fundamental aspects of social networks. One particular metric could be social network characteristics integration, as integrating social media aspects into an organisation's characteristics can make use of its infrastructure and supporting functions.

Another potential aspect to be considered is ecosystem interoperability, or the capacity for instant collaboration among ecosystems and the entities within them (Koussouris et al., 2011). It requires independent entities to formulate a virtual structure to meet specific requirements, such as business ecosystems interoperation, business strategy alignment and information-sharing within a virtual enterprise (Davies \& Fisher, 2020). Business ecosystem interoperation ensures that all ecosystems can cooperate dynamically, and the virtual enterprise automatically enables collaboration at all business levels. 
Finally, although the interviewees and survey participants realise the importance of interoperability among business processes, further aspects may add value to the SIEF from a regulatory perspective, for instance jurisdictional restrictions, strict laws and regulations (Palmer et al., 2018).

\subsection{Theoretical contributions}

Theoretical contributions were integrated into the entire study, as described. This article presents an original semiotics-based framework for evaluating interoperability, promoting information-sharing among business processes. Unlike other interoperability evaluation approaches, the SIEF is based on the semiotic framework (Liu, 2000), although this has until now articulated only communication processes and has never yet been extended to the study of interoperability assessment among business processes. We adopted the concept of semiotic interoperability since our previous state-of-the-art analysis of existing interoperability evaluation frameworks revealed that most do not fully address interoperability issues at the pragmatic level, where an organisation's business processes, policies, behaviour and culture are considered. The SIEF is dedicated to evaluating interoperability among business processes from the pragmatic interoperability perspective. The concept of semiotic interoperability provides a holistic view of interoperability evaluation on six levels (physical, empirical, syntactic, semantic, pragmatic and social), and it deals with interoperability not only from a technical but from pragmatic and social perspectives, which are closely related to business, people and the social environment. The results of the evaluation list the current interoperability issues that an organisation should address to achieve better collaboration.

A further theoretical contribution embraces the application of organisational semiotics theory, from information system design to the domain of interoperability. The semiotic framework, from organisational semiotics, builds on the theoretical foundation of the SIEF, while organisation morphology, also from organisational semiotics, guides the development of metrics and interoperability evaluation among business processes. Further key concepts from organisational semiotics, such as affordance and agency (Askool, 2018), have inspired and contributed to this study.

\subsection{Implications for practice}

The practical contribution of this study is application of the SIEF in a case study. The results of the interoperability evaluation between two business processes provide not just a list of scores for the current interoperability at the technical, formal and informal levels but full details. The analysis, presented in figures, identifies the specific areas that the organisation should improve. Comparing the participants' two perspectives reveals scope for an in-depth interpretation of the data. A project manager or senior manager receiving these views with a separate analysis of their interoperability will be empowered to appreciate the bigger picture of process collaboration.

Interoperability is often seen as a measure to address the integration of only technical systems (Novo \& Francesco, 2020) and most studies, as shown in our previous comparative analysis, do not fully address 
interoperability issues at the pragmatic level, where organisation's business processes, policies, behaviour and culture are considered. Therefore, a bottom-up approach, starting with technical interoperability then progressing to the pragmatic and social levels, is necessary to promote interoperability across business processes. In this context, since so few studies attempt to assess them, pragmatic and social interoperability deserve higher priority than other interoperability levels. The SIEF addresses the attributes relevant to several levels of interoperability - technical, syntactic, semantic, pragmatic and social - since assessment cannot be realised by addressing only the data on technical interoperability issues. To apply the SIEF in a business context, an evaluation should be supported because it will achieve a more concrete understanding of an organisation's policies, structure, behaviour patterns, cultural and social attributes (Gottschalk, 2020). The result of the case study has positively shown that using metrics for interoperability assessment is applicable and useful, yet there is a need to extend this study to generalise its usefulness for business processes to other domains. It is noted that the objectivity of each metric is important, as the pondering coefficient depends on the time-to-time organisational setting.

In comparison with similar approaches developed to study interoperability, for instance the enterprise interoperability framework (Chen \& Daclin, 2006; Molina \& Panetto, 2007), the interoperability score (Ford \& Colombi, 2007) and the government interoperability maturity matrix (Sarantis et al., 2008), the SIEF covers a wide range of assessment, especially at the formal and informal levels. For example, business strategy, management of external relationships, management style, employee motivation and honesty and cultural influence are metrics that other approaches have not considered. The proposed SIEF can be used in combination with existing interoperability approaches for information systems planning, especially for new information system design across dissimilar organisations, such as connected systems for health and social care services. The SIEF can be used to analyse the informal environment of the organisation as its mission and goal, as well as giving insights into interoperability's impact on the value network. Furthermore, interoperability evaluation results can inform an organisation's objectives, power structure and culture relating to interoperability among other organisations (Leal et al., 2019). Through the interoperability evaluation of organisation structure, resource allocation mechanism, management processes and functional capabilities, the SIEF can reform organisational structure and business processes, formally define roles and responsibilities between the organisations and plan activities for changes relating to interoperability. These attributes contribute to the identification of inter-organisational information requirements, including the overall information architecture and potential information needs (Muller et al., 2019).

Last but not least, the SIEF can evaluate emerging technical capabilities, an information system's stage of adoption and the blueprint of skills development for technical interoperability. These can contribute to specific information communication technology strategies, such as hardware, software and network plans (Costin \& Eastman, 2019). The interoperability assessment outcomes of informal, formal and technical systems can be transformed into input for the formulation of an information system strategy. 


\section{Conclusion, Limitations and Future Research}

This article presents the SIEF, together with a group of metrics for measuring interoperability. The SIEF offers a means of measuring, analysing and assessing interoperability among business processes. A feasibility study was conducted to develop the SIEF's metrics, and the SIEF was then applied in a case study to assess the interoperability between two business processes within an organisation. The results identified the interoperability concerns that should be addressed properly to support better collaboration among business processes. Standards should then be created accordingly, and need to be adhered to by an organisation to ensure success with its interoperability issues. This study has constructed hypotheses, proposed a theoretical framework and validated it in practice. Its limitations are twofold: the theoretical limitations to the framework's philosophical and methodological stance; and the practical limitations to its application.

The study adopts the interpretivist paradigm and takes qualitative research as its overall strategy to investigate the research questions. Historically, qualitative studies have often been regarded by the sciences as 'lacking rigor, as well as dependability and precision' compared with quantitative studies (Sechrest, 1992). Hence, empirical investigations within the sciences have typically given preference to quantitative rather than qualitative research methodologies. Similarly, positivist research has largely been given preference over interpretivist research, due to the appeal of its generalisability as well as the fact that, broadly speaking, empirically it is significantly less time consuming to investigate. The interpretivist paradigm provides greater scope for interpreting the world in a more subjective and contextual way, and it is often described as holistic, emic, contextualised, interpretive and immersed (Holloway \& Wheeler, 2010). Moreover, interpretivism frees research from making the restrictive and often unrealistic assumptions necessary to positivist research, including independence of the theory from the observations and between the observations and the values (Guba \& Lincoln, 1994).

To tackle these issues, more progress is needed in developing conceptual frameworks and algorithmic methods and creating techniques such as semantic reconciliation and mediation. The SIEF proposed in this article, together with the proofs-of-concept proposed in our previous study, should be validated in other domains to examine its offer. However, this experiment-oriented approach needs to be carefully selected to cover real-life situations in the enterprise environment (Koussouris et al., 2011). The knowledge base of interoperability barriers involves not only the semantics and technical functions normally used to construct a common dictionary to support the operation of information-sharing among various business processes but other facets, ranging from business processes alignment to context awareness (Motta et al., 2019). To apply the SIEF in other domains, we need to investigate the knowledge base of interoperability barriers, technical standards, methods, tools and large-scale experimentation.

In regard to the practical limitations of this research, interoperability among business processes encompasses many aspects. The SIEF provides a set of metrics for evaluation, but the selection of the 
relevant metrics can vary from organisation to organisation. Besides, the process of collecting data in a case study is resource intensive. Focusing on a limited number of relevant metrics is recommended, when possible, to avoid time-consuming and expensive data collection. The results of the case study have positively indicated that a metrics for interoperability assessment is both applicable and useful, yet there is a need to extend this study to generalise its usefulness to business processes in other domains. It is noted that the objectivity of each metric is important, as the pondering coefficient varies according to the time-to-time organisational setting. The collected data may be biased because the participants are unable to interpret and understand the outcomes due to their lack of awareness of the context. In addition, information-sharing is not only concentrated in documents and tangible communication but relies heavily on the individuals operating as part of a business unit (Koussouris et al., 2011). Therefore, when applying the SIEF to other domains, it may be that results of an interoperability evaluation vary.

To overcome these practical limitations, more progress should be made in terms of applying the SIEF in various business domains to evaluate and improve their offer. More agile metrics should be developed to adapt to each specific domain. Customised guidelines should be employed to select the appropriate metrics to generate the interoperability assessment model. The evaluation technique should consider using emerging technologies to provide semi-automatic tools for metric assessment and data mapping (Hardjono et al., 2019). When using the SIEF in a business context, the existing standards for implementing interoperability should be considered to enhance the structure of interoperability, and it is vital to ensure consistency and to avoid redundancy (Onar et al., 2019). Furthermore, organisations are becoming more transparent, with more smarter ecosystems. There is a need for the SIEF to devise standards for developing metrics (Kelly et al., 2020), and the evaluation technique should become more standardised to adapt to future contexts. Future work on this study will probe the feasibility of metric standardisation for the evaluation of interoperability.

\section{References}

Abel, F., Henze, N., \& Krause, D., 2009. Social Semantic Web at Work: Annotating and grouping social media content, web information systems and technologies, pp. 199-213. Berlin: Springer.

Agostinho, C., Ducq, Y., Zacharewicz, G., Sarraipa, J., Lampathaki, F., Poler, R., \& Jardim-Goncalves, R., 2016. Towards a sustainable interoperability in networked enterprise information systems: trends of knowledge and model-driven technology. Computers in Industry, 79, 64-76.

Anwaar, F., Iltaf, N., Afzal, H., \& Nawaz, R., 2018. HRS-CE: A hybrid framework to integrate content embeddings in recommender systems for cold start items. Journal of Computational Science, 29, 9-18.

Askool, S. 2018. Extending technology acceptance model for proximity mobile payment via organisational semiotics. In Digitalisation, Innovation, and Transformation: 18th IFIP WG 8.1 International Conference on Informatics and Semiotics in Organisations, ICISO 2018, Reading, UK. 
Ayyaz, S., Qamar, U., \& Nawaz, R. 2018. HCF-CRS: A hybrid content based fuzzy conformal recommender system for providing recommendations with confidence. PloS One, 13(10).

Bannister, F., 2007. The curse of the benchmark: An assessment of the validity and value of egovernment comparisons. International Review of Administrative Sciences, 73(2), 171-188.

Barbarito, F., Pinciroli, F., Mason, J., Marceglia, S., Mazzola, L., \& Bonacina, S., 2012. Implementing standards for the interoperability among healthcare providers in the public regionalized healthcare information system of the Lombardy region. J. Biomed. Inform. 45, 736-45.

Batista-Navarro, R. T., Kontonatsios, G., Mihăilă, C., Thompson, P., Rak, R., Nawaz, R., Korkontzelos, L., \& Ananiadou, S., 2013. Facilitating the analysis of discourse phenomena in an interoperable NLP platform. In International Conference on Intelligent Text Processing and Computational Linguistics, pp. 559-571. Berlin: Springer.

Boonstra, A., Broekhuis, M., Offenbeek, M. Van, \& Wortmann, H., 2011. Strategic alternatives in telecare design: Developing a value-configuration-based alignment framework. Journal of Strategy Information Systems. 20, 198-214.

Bouloukakis, G., Georgantas, N., Ntumba, P., \& Issarny, V., 2019. Automated synthesis of mediators for middleware-layer protocol interoperability in the IoT. Future Generation Computer Systems, 101, 1271-1294.

Chen, D., Doumeingts, G., \& Vernadat, F., 2008. Architectures for enterprise integration and interoperability: Past, present and future. Comput. Ind. 59, 647-659.

Chen, D. \& Daclin, N., 2006. Framework for enterprise interoperability. Proc. IFAC Work. EI2N.

Costin, A. \& Eastman, C., 2019. Need for interoperability to enable seamless information exchanges in smart and sustainable urban systems. Journal of Computing in Civil Engineering, 33(3), 04019008.

Cornu, C., Chapurlat, V., Quiot, J., \& Irigoin, F., 2012. Customizable interoperability assessment methodology to support technical processes deployment in large companies. Annual Review Control 36, 300-308.

Davies, J. \& Fisher, M., 2020. Data platforms: Interoperability and insight. In J. Davies \& C. Fortuna, The Internet of Things: From data to insight, pp. 37-50. https://doi.org/10.1002/9781119545293.ch4

Dutot, V., Bergeron, F., \& Raymond, L., 2014. Information management for the internationalization of SMEs: An exploratory study based on a strategic alignment perspective. International Journal of Information Management, 34(5), 672-681, ISSN 0268-4012.

EN/ISO I9439, 2003. EN/ISO Enterprise integration - Framework for enterprise modelling. Work 
report.

Ford, T. \& Colombi, J., 2007. The interoperability score. In Proc. Fifth Conf. Syst. Eng. Res., pp. 1-10.

Froger, M., Bénaben, F., Truptil, S., Boissel-Dallier, N., 2019. A non-linear business process management maturity framework to apprehend future challenges. International Journal of Information Management, 49, 290-300, ISSN 0268-4012.

Gottschalk, P., 2020. E-government interoperability and information resource integration: Frameworks for aligned development. Information Systems, 193.

Gregory, S., Dixon, A., \& Ham, C., 2012. Health Policy under the Coalition Government: A mid-term assessment. London: King's Fund.

Hardjono, T., Lipton, A., \& Pentland, A., 2019. Toward an interoperability architecture for blockchain autonomous systems. IEEE Transactions on Engineering Management, 99, 1-12.

Hevner, A., March, S., Park, J., \& Ram, S., 2004. Design science in information systems research. MIS Q., 28, 75-105.

Hu, Y., Chang, I., \& Hsu, W., 2017. Mediating effects of business process for international trade industry on the relationship between information capital and company performance. International Journal of Information Management, 37(5), 473-483, ISSN 0268-4012.

Kasunic, M. \& Anderson, W., 2004. Measuring Systems Interoperability: Challenges and opportunities. Technical note. Pittsburgh: Software Engineering Institute, Carnegie Mellon University.

Kaye, D., 2003. Loosely Coupled: The missing pieces of web services. Marin County: RDS Press.

Kelly, Y.P., Kuperman, G.J., Steele, D.J., \& Mendu, M.L., 2020. Interoperability and patient electronic health record accessibility: Opportunities to improve care delivery for dialysis patients. American Journal of Kidney Diseases, S0272-6386(19), 31129-1. doi: 10.1053/j.ajkd.2019.11.001

Koens, T. \& Poll, E., 2019. Assessing interoperability solutions for distributed ledgers. Pervasive and Mobile Computing, 59, 101079.

Koussouris, S., Lampathaki, F., Mouzakitis, S., Charalabidis, Y., \& Psarras, J., 2011. Digging into the real-life enterprise interoperability areas definition and overview of the main research areas. In: Proceedings of CENT, 19-22.

LaVean, G., 1980. Interoperability in defense communications. IEEE Transactions on Communications, 28(9), 1445-1455. 
Leal, G.S.S., Guédria, W., \& Panetto, H., 2019. Interoperability assessment: A systematic literature review. Computers in Industry, 106, 111-132.

Leal, G.S.S., Guédria, W., Panetto, H., \& Proper, E., 2017. An approach for interoperability assessment in networked enterprises. In 20th IFAC World Congress. IFAC.

Li, W., 2010. The architecture and implementation of digital hospital - information system integration for seamless business process. PhD thesis, Beijing Institute of Technology.

Li, W., Liu, K., \& Liu, S., 2013. Semiotic interoperability - a critical step towards systems integration. In 5th International Conference on Knowledge Management and Information Sharing, Vilamoura, Portugal.

Lincoln, Y., \& Guba, E., 1985. Naturalistic Inquiry. Beverly Hills, CA: Sage.

Liu, K., 2000. Semiotics in Information Systems Engineering. Cambridge: Cambridge University Press.

Liu, K., 2005. Requirements reengineering from legacy information systems using semiotic techniques. Syst. Signs Actions International Journal of Communication Information Technology, 11, 38-61.

Liu, S., Li, W., \& Liu, K., 2014a. Assessing pragmatic interoperability of information systems from a semiotic perspective. In 15th International Conference on Informatics and Semiotics in Organisation (ICISO), Shanghai.

Liu, S., Li, W., \& Liu, K., 2014b. Pragmatic oriented data interoperability for smart healthcare information systems. In 14th IEEE/ACM International Symposium on Cluster, Cloud and Grid Computing, Chicago.

Liu, S., Li, W., \& Liu, K., 2015. Assessing pragmatic interoperability for process alignment in collaborative working environment. In 16th International Conference on Informatics and Semiotics in Organisation, Toulouse.

Liu, S., Li, W., Liu, K., \& Han, J., 2013. Evaluation frameworks for information systems integration: from a semiotic lens. In 3rd International Conference on Logistics, Informatics and Service Science, Reading, UK.

Molina, A. \& Panetto, H., 2007. Enterprise integration and networking: Challenges and trends. Stud. Informatics Control, 16, 353-368.

Moon, Y., Choi, M., \& Armstrong, D., 2018. The impact of relational leadership and social alignment on information security system effectiveness in Korean governmental organizations. International Journal of Information Management, 40, 54-66, ISSN 0268-4012. 
Motta, R.C., de Oliveira, K.M., \& Travassos, G.H., 2019. A conceptual perspective on interoperability in context-aware software systems. Information and Software Technology, 114, 231-257.

Muller, M.F., Esmanioto, F., Huber, N., Loures, E.R., \& Junior, O.C., 2019. A systematic literature review of interoperability in the green building information modeling lifecycle. Journal of Cleaner Production, 223, 397-412.

Nawaz, R., Thompson, P., \& Ananiadou, S., 2013. Negated bio-events: Analysis and identification. BMC Bioinformatics, 14(1), 14.

Nawaz, R., Thompson, P., McNaught, J., \& Ananiadou, S., 2010. Meta-knowledge annotation of bioevents. In LREC (International Conference on Language Resources and Evaluation), 2498-2507.

Nielsen, J., 1994. Heuristic evaluation. In J. Nielsen \& R.L. Mack (eds), Usability Inspection Methods. New York: John Wiley \& Sons.

Novo, O. \& Francesco, M.D., 2020. Semantic interoperability in the IoT: Extending the web of things architecture. ACM Transactions on Internet of Things, 1(1), 1-25.

Onar, O.C., Chinthavali, M., Campbell, S.L., Seiber, L.E., \& White, C.P., 2019. Vehicular integration of wireless power transfer systems and hardware interoperability case studies. IEEE Transactions on Industry Applications, 55(5), 5223-5234.

Palmer, C., Urwin, E.N., Niknejad, A. et al., 2018. An ontology supported risk assessment approach for the intelligent configuration of supply networks. J. Intell. Manuf., 29, 1005-1030.

Palomares, N., Campos, C., \& Palomero, S., 2010. How to develop a questionnaire in order to measure interoperability levels in enterprises. In: K. Popplewell, J. Harding, R. Poler \& R. Chalmeta (eds), Enterprise Interoperability, vol. IV, pp. 387-396. London: Springer.

Qadir, H., Khalid, O., Khan, M. U., Khan, A. U. R., \& Nawaz, R., 2018. An optimal ride-sharing recommendation framework for carpooling services. IEEE Access, 6, 62296-62313.

Rahimi, F., Møller, C., \& Hvam, L., 2016. Business process management and IT management: The missing integration. International Journal of Information Management, 36(1), 142-154, ISSN 02684012 .

Romero, D. \& Molina, A., 2011. Collaborative networked organisations and customer communities: value co-creation and co-innovation in the networking era. Prod. Plan. Control, 22, 447-472.

Sarantis, D., Charalabidis, Y., \& Psarras, J., 2008. Towards standardising interoperability levels for information systems of public administrations. Electronic Journal for E-commerce Tools \& Applications eJETA, special issue: Interoperability for Enterprises and Administrations Worldwide, 2. 
Saturno, M., Ramos, L.F.P., Polato, F., Deschamps, F., \& Freitas Rocha Loures, E., 2017. Evaluation of interoperability between automation systems using multi-criteria methods. Procedia Manuf., 11 $1837-1845$

Seawright, J., \& Gerring, J., 2008. Case selection techniques in case study research: A menu of qualitative and quantitative options. Political Research Quarterly, 61(2), 294-308.

Shao, Z., 2019. Interaction effect of strategic leadership behaviors and organizational culture on ISbusiness strategic alignment and enterprise systems assimilation. International Journal of Information Management, 44, 96-108, ISSN 0268-4012.

Škrinjar, R. \& Trkman, P., 2013. Increasing process orientation with business process management: Critical practices. International Journal of Information Management, 33(1), 48-60, ISSN 0268-4012.

Stamper, R., 1973. Information in Business and Administrative Systems. London: Batsford.

Thompson, P., Nawaz, R., McNaught, J., \& Ananiadou, S., 2017. Enriching news events with metaknowledge information. Language Resources and Evaluation, 51(2), 409-438.

Thompson, P., Nawaz, R., Korkontzelos, I., Black, W., McNaught, J., \& Ananiadou, S., 2013. News search using discourse analytics. In Digital Heritage International Congress, 1, 597-604.

Yin, R., 2003. Case study research: Design and methods. Sage.

Yunus, R., Arif, O., Afzal, H., Amjad, M. F., Abbas, H., Bokhari, H. N., Haider, S. T., Zafar, N., \& Nawaz, R., 2018. A framework to estimate the nutritional value of food in real time using deep learning techniques. IEEE Access, 7, 2643-2652.

Zutshi, A., Grilo, A., \& Jardim-Goncalves, R., 2012. The business interoperability quotient measurement model. Comput. Ind., 63, 389-404. 
APPENDIX I

Table 8 Results of interoperability assessment at the technical level

\begin{tabular}{|c|c|c|c|c|c|c|c|c|c|c|c|c|c|}
\hline \multirow{3}{*}{$\begin{array}{l}\text { Technical level } \\
\text { Metric }\end{array}$} & \multirow{3}{*}{$\begin{array}{l}\text { Abbreviation } \\
\mathbf{T}_{\mathbf{i}}\end{array}$} & \multicolumn{4}{|c|}{ Overall interoperability score } & \multicolumn{4}{|c|}{$\begin{array}{l}\text { Interoperability score (NPD } \\
\text { perspective) }\end{array}$} & \multicolumn{4}{|c|}{$\begin{array}{l}\text { Interoperability score (DTO } \\
\text { perspective) }\end{array}$} \\
\hline & & \multicolumn{2}{|c|}{$\begin{array}{l}\text { Pondering } \\
\text { coefficient } \\
\alpha_{\mathrm{i}} \in[0,1]\end{array}$} & \multicolumn{2}{|c|}{$\begin{array}{l}\text { Assessment } \\
\text { score } \\
\text { TS } \\
\mathbf{i} \in[0,4]\end{array}$} & \multicolumn{2}{|c|}{$\begin{array}{l}\text { Pondering } \\
\text { coefficient } \\
\alpha_{i} \in[0,1]\end{array}$} & \multicolumn{2}{|c|}{$\begin{array}{l}\text { Assessment score } \\
\text { TS }_{\mathbf{i}} \in[0,4]\end{array}$} & \multicolumn{2}{|c|}{$\begin{array}{l}\text { Pondering } \\
\text { coefficient } \\
\alpha_{\mathrm{i}} \in[0,1]\end{array}$} & \multicolumn{2}{|c|}{$\begin{array}{l}\text { Assessment score } \\
\text { TS }_{\mathbf{i}} \in[0,4]\end{array}$} \\
\hline & & (Mean) & $(\mathbf{S t d})$ & (Mean) & (Std) & (Mean) & (Std) & (Mean) & $($ Std $)$ & (Mean) & $($ Std $)$ & (Mean) & (Std) \\
\hline \multicolumn{14}{|c|}{ Modelling business document } \\
\hline High-level model & $\mathrm{T}_{1}$ & $\alpha_{1}=0.959$ & 0.080 & $\mathrm{TS}_{1}=3.274$ & 0.563 & $\alpha_{1}=0.967$ & 0.074 & $\mathrm{TS}_{1}=3.432$ & 0.467 & $\alpha_{1}=0.913$ & 0.089 & $\mathrm{TS}_{1}=3.251$ & 0.537 \\
\hline Components model & $\mathrm{T}_{2}$ & $\alpha_{2}=0.891$ & 0.155 & $\mathrm{TS}_{2}=2.779$ & 0.423 & $\alpha_{2}=0.921$ & 0.097 & $\mathrm{TS}_{2}=2.843$ & 0.487 & $\alpha_{2}=0.879$ & 0.108 & $\mathrm{TS}_{2}=$ & 0.498 \\
\hline \multicolumn{14}{|c|}{ Implementation of data integration } \\
\hline $\begin{array}{l}\text { Source and target data } \\
\text { format definition }\end{array}$ & $\mathrm{T}_{3}$ & $\alpha_{3}=0.894$ & 0.153 & $\mathrm{TS}_{3}=3.363$ & 0.488 & $\alpha_{3}=0.932$ & 0.083 & $\mathrm{TS}_{3}=3$ & 0.413 & $\alpha_{3}=0.853$ & 0.121 & $\mathrm{TS}_{3}=3.042$ & 0.674 \\
\hline $\begin{array}{l}\text { Data mapping and } \\
\text { transformation }\end{array}$ & $\mathrm{T}_{4}$ & $\alpha_{4}=0.898$ & 0.141 & $\mathrm{TS}_{4}=$ & 0.519 & $\alpha_{4}=0.935$ & 0.081 & $\mathrm{TS}_{4}=3$ & 0.487 & $\alpha_{4}=0.871$ & 0.126 & $\mathrm{TS}_{4}=3.193$ & 0.491 \\
\hline \multicolumn{14}{|c|}{ Implementation of service integration } \\
\hline $\begin{array}{l}\text { Development on } \\
\text { execution }\end{array}$ & $\mathrm{T}_{5}$ & & & & & & & & & & & & \\
\hline $\begin{array}{l}\text { infrastructure } \\
\text { Services for }\end{array}$ & $\mathrm{T}_{6}$ & $\alpha_{5}=0.833$ & 0.173 & $\mathrm{TS}_{5}=3.101$ & 0.595 & $\alpha_{5}=0.898$ & 0.091 & $\mathrm{TS}_{5}=3.263$ & 0.514 & $\alpha_{5}=0.805$ & 0.166 & $\mathrm{TS}_{5}=3.077$ & 0.520 \\
\hline connecting proc & & $\alpha_{6}=0.912$ & 0.091 & $\mathrm{TS}_{6}=3.261$ & 0.553 & $\alpha_{6}=0.928$ & 0.085 & $\mathrm{TS}_{6}=3.301$ & 0.521 & $\alpha_{6}=0.894$ & 0.086 & $\mathrm{TS}_{6}=3.138$ & 0.504 \\
\hline $\begin{array}{l}\text { Services for message } \\
\text { exchange }\end{array}$ & $\mathrm{T}_{7}$ & $\alpha_{7}=0.917$ & 0.096 & $\mathrm{TS}_{7}=3.256$ & 0.552 & $\alpha_{7}=0.933$ & 0.086 & $\mathrm{TS}_{7}=3.323$ & 0.529 & $\alpha_{7}=0.889$ & 0.098 & $\mathrm{TS}_{7}=3.256$ & 0.491 \\
\hline \multicolumn{14}{|l|}{ Business semantics } \\
\hline Define o & $\mathrm{T}_{8}$ & $\alpha_{8}=0.774$ & 0.135 & $\mathrm{TS}_{8}=2.472$ & 0.661 & $\alpha_{8}=0.834$ & 0.099 & $\mathrm{TS}_{8}=2.790$ & 0.639 & $\alpha_{8}=0.745$ & 0.141 & $\mathrm{TS}_{8}=2.182$ & 0.692 \\
\hline Semantic conversion & $\mathrm{T}_{9}$ & $\alpha_{9}=0.735$ & 0.149 & $\mathrm{TS}_{9}=2.310$ & 0.479 & $\alpha_{9}=0.828$ & 0.103 & $\mathrm{TS}_{9}=2.844$ & 0.403 & $\alpha_{9}=0.712$ & 0.150 & $\mathrm{TS}_{9}=2.017$ & 0.673 \\
\hline
\end{tabular}


Table 9 Results of interoperability assessment at the formal level

\begin{tabular}{|c|c|c|c|c|c|c|c|c|c|c|c|c|c|}
\hline \multirow{3}{*}{$\begin{array}{l}\text { Formal level } \\
\text { Metric } \\
\text { (Performance measure) }\end{array}$} & \multicolumn{5}{|c|}{ Overall interoperability score } & \multicolumn{4}{|c|}{$\begin{array}{l}\text { Interoperability score (NPD } \\
\text { perspective) }\end{array}$} & \multicolumn{4}{|c|}{ Interoperability score (DTO } \\
\hline & \multirow{2}{*}{ 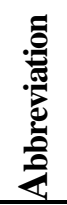 } & \multirow{2}{*}{$\begin{array}{l}\text { Pondering } \\
\text { coefficient } \\
\delta_{\mathrm{i}} \in[0,1] \\
(\text { Mean })\end{array}$} & \multirow{2}{*}{ (Std) } & \multirow{2}{*}{$\begin{array}{l}\text { Assessment } \\
\text { score } \\
\text { FS } i \in[0,4] \\
\text { (Mean) }\end{array}$} & \multirow[b]{2}{*}{ (Std) } & \multicolumn{2}{|l|}{$\begin{array}{l}\text { Pondering } \\
\text { coefficient } \\
\delta_{\mathrm{i}} \in[0,1]\end{array}$} & \multicolumn{2}{|c|}{$\begin{array}{l}\text { Assessment score } \\
\text { FS } i \in[0,4]\end{array}$} & \multicolumn{2}{|c|}{$\begin{array}{l}\text { Pondering } \\
\text { coefficient } \\
\delta_{i} \in[0,1]\end{array}$} & \multicolumn{2}{|c|}{$\begin{array}{l}\text { Assessment score } \\
\text { FS } i \in[0,4]\end{array}$} \\
\hline & & & & & & (Mean) & (Std) & $(\mathbf{M}$ & (Std) & (Mean) & (Std) & (Mean) & (Std) \\
\hline \multicolumn{14}{|l|}{ Business st } \\
\hline & $\mathrm{F}_{1}$ & ${ }_{1}=0.962$ & 0.078 & $\mathrm{FS}_{1}=3.358$ & 0.647 & $\delta_{1}=0.981$ & 0.065 & $\mathrm{FS}_{1}=3.369$ & 0.601 & $\delta_{1}=0.952$ & 0.068 & $\mathrm{FS}_{1}=3.347$ & 0.662 \\
\hline prev & & & & & & & & & & & & & \\
\hline & & $2=0$. & 1.147 & $\mathrm{FS}_{2}=2.830$ & 0.719 & $\delta_{2}=0.811$ & 0.093 & $\mathrm{FS}_{2}=2.963$ & 0.702 & $\delta_{2}=0.829$ & 0.017 & $\mathrm{FS}_{2}=2.711$ & 0.709 \\
\hline Backup strategic plan & $\mathrm{F}_{3}$ & $\delta_{3}=0$. & 0.071 & $\mathrm{FS}_{3}=3.094$ & 0.783 & $\delta_{3}=0.967$ & 0.062 & $\mathrm{FS}_{3}=3.243$ & 0.724 & $\delta_{3}=0.941$ & 0.064 & $\mathrm{FS}_{3}=2$ & 0.715 \\
\hline \multicolumn{14}{|c|}{ Management of external relationships } \\
\hline Partner selection & $\mathrm{F}_{4}$ & $\delta_{4}=0$ & 0.093 & 54 & 0.484 & $\delta_{4}=0$ & 0.087 & $\mathrm{FS}$ & 0.769 & $\delta_{4}=0.892$ & 0.077 & $\mathrm{FS}_{4}$ & 0.559 \\
\hline Partı & $\mathrm{F}_{5}$ & 64 & 0.093 & $\mathrm{FS}_{5}=$ & 0.484 & $s=0.811$ & 0.087 & $\mathrm{FS}_{5}=$ & 0.743 & $\delta_{5}=0.892$ & 0.077 & $\mathrm{FS}_{5}$ & 0.541 \\
\hline Oper & $\mathrm{F}_{6}$ & 75 & 0.064 & $\mathrm{FS}_{6}=3.241$ & 0.573 & $\delta_{6}=0.961$ & 0.061 & $\mathrm{FS}_{6}=3.128$ & 0.582 & $\delta_{6}=0.988$ & 0.056 & $\mathrm{FS}_{6}=3$ & 0.534 \\
\hline Con & $\mathrm{F}_{7}$ & 42 & 0.070 & $\mathrm{FS}_{7}=2.357$ & 0.815 & ${ }_{7}=0.906$ & 0.079 & $\mathrm{FS}_{7}=2.129$ & 0.892 & $\delta_{7}=0.973$ & 0.043 & $\mathrm{FS}_{7}=2.548$ & 0.821 \\
\hline Communication & $\mathrm{F}_{8}$ & $\delta_{8}=0.899$ & 0.098 & 59 & 0.748 & $\delta_{8}=0.812$ & 0.072 & $\mathrm{FS}_{8}=2.461$ & 0.649 & $\delta_{8}=0.963$ & 0.091 & $\mathrm{FS}_{8}=$ & 0.691 \\
\hline \multicolumn{14}{|c|}{ Collaborative business processes management } \\
\hline Clarity in responsibility & $\mathrm{F}_{9}$ & $\delta_{9}=0.966$ & 0.065 & 82 & 0.533 & 0.971 & 0.063 & 1 & 31 & 59 & 0.067 & 1 (N9 & .512 \\
\hline Busin & $\mathrm{F}_{10}$ & $\delta_{10}=0.812$ & 1.154 & $\mathrm{FS}_{10}=3.017$ & 0.658 & $\delta_{10}=0.839$ & 0.151 & $\mathrm{FS}_{10}=3.126$ & 0.651 & $\delta_{10}=0.891$ & 0.143 & $\mathrm{FS}_{10}=$ & 0.603 \\
\hline Clarity i & $\mathrm{F}_{11}$ & $\delta_{11}=0.825$ & 1.159 & $\mathrm{FS}_{11}=3.334$ & 0.515 & $\delta_{11}=0.841$ & 0.136 & $\mathrm{FS}_{11}=3.457$ & 0.512 & $\delta_{11}=0.804$ & 0.127 & $\mathrm{FS}_{11}=3.231$ & 0.504 \\
\hline Process visibility & $\mathrm{F}_{12}$ & & 0.212 & $\mathrm{FS}_{12}=2.396$ & 0.761 & $\delta_{12}=0.702$ & 0.192 & $\mathrm{FS}_{12}=2.675$ & 0.771 & $\delta_{12}=0.529$ & 0.237 & $\mathrm{FS}_{12}=2$ & 0.705 \\
\hline \multicolumn{14}{|l|}{ IPR management } \\
\hline IPR & & $\delta_{13}=0.936$ & 0.093 & $\Gamma \mathrm{S}_{13}=$ & 0.489 & $\delta_{13}=0.945$ & 0.087 & $\mathrm{~F} 13=5.531$ & 0.436 & $\delta_{13}=0.927$ & 0.091 & $\mathrm{FS}_{13}=$ & 0.486 \\
\hline Potent & $\mathrm{F}_{14}$ & $\delta_{14}=0.943$ & 0.090 & $\mathrm{FS}_{14}=2.766$ & 0.693 & $\delta_{14}=0.957$ & 0.089 & $\mathrm{FS}_{14}=2.897$ & 0.681 & $\delta_{14}=0.932$ & 0.083 & $\mathrm{FS}_{14}=2.653$ & 0.694 \\
\hline IPR conflict & $F_{15}$ & $\delta_{15}=0.962$ & 0.078 & $\mathrm{FS}_{15}=2.485$ & 0.636 & $\delta_{15}=0.936$ & 0.071 & $\mathrm{FS}_{15}=2.801$ & 0.656 & $\delta_{15}=0.982$ & 0.076 & $\mathrm{FS}_{15}=2.053$ & 0.621 \\
\hline \multicolumn{14}{|l|}{ Organisational structure } \\
\hline Organisational role mapping & $\mathrm{F}$ & $\delta_{16}=0.857$ & 0.090 & $\mathrm{FS}_{16}=2.884$ & 0.745 & $\delta_{16}=0.871$ & 0.085 & $\mathrm{FS}_{16}=3.013$ & 0.704 & $\delta_{16}=0.830$ & 0.081 & $\mathrm{FS}_{16}=2.634$ & 0.721 \\
\hline
\end{tabular}


Table 10 Results of interoperability assessment at the informal level

\begin{tabular}{|c|c|c|c|c|c|c|c|c|c|c|c|c|c|}
\hline \multirow{3}{*}{$\begin{array}{l}\text { Informal level } \\
\text { Metric } \\
\text { (Indicator) }\end{array}$} & \multirow{3}{*}{$\begin{array}{l}\text { Abbreviation } \\
\mathbf{M i}\end{array}$} & \multicolumn{4}{|c|}{ Overall interoperability score } & \multicolumn{4}{|c|}{$\begin{array}{l}\text { Interoperability score (NPD } \\
\text { perspective) }\end{array}$} & \multicolumn{4}{|c|}{$\begin{array}{l}\text { Interoperability score (DTO } \\
\text { perspective) }\end{array}$} \\
\hline & & \multicolumn{2}{|c|}{$\begin{array}{l}\text { Pondering } \\
\text { coefficient } \\
\beta_{\mathrm{i}} \in[0,1]\end{array}$} & \multicolumn{2}{|l|}{$\begin{array}{l}\text { Assessment } \\
\text { score } \\
\text { MS }_{\mathbf{i}} \in[0,4]\end{array}$} & \multicolumn{2}{|c|}{$\begin{array}{l}\text { Pondering } \\
\text { coefficient } \\
\beta_{i} \in[0,1]\end{array}$} & \multicolumn{2}{|c|}{$\begin{array}{l}\text { Assessment score } \\
\mathbf{M S}_{\mathrm{i}} \in[\mathbf{0 , 4}]\end{array}$} & \multicolumn{2}{|c|}{$\begin{array}{l}\text { Pondering } \\
\text { coefficient } \\
\beta_{\mathrm{i}} \in[0,1]\end{array}$} & \multicolumn{2}{|c|}{$\begin{array}{l}\text { Assessment score } \\
\mathbf{M S}_{\mathrm{i}} \in[0,4]\end{array}$} \\
\hline & & (Mean) & (Std) & (Mean) & (Std) & (Mean) & $($ Std $)$ & (Mean) & $($ Std $)$ & (Mean) & (Std) & (Mean) & (Std) \\
\hline $\begin{array}{l}\text { Tradition and } \\
\text { culture }\end{array}$ & $\mathrm{M}_{1}$ & $\beta_{1}=0.653$ & 0.088 & $\mathrm{MS}_{1}=2.363$ & 0.481 & $\beta_{1}=0.571$ & 0.063 & $\mathrm{MS}_{1}=2.409$ & 0.493 & $\beta_{1}=0.713$ & 0.081 & $\mathrm{MS}_{1}=2.313$ & 0.485 \\
\hline Management style & $\mathrm{M}_{2}$ & $\beta_{2}=0.725$ & 0.097 & $\mathrm{MS}_{2}=2.472$ & 0.716 & $\beta_{2}=0.739$ & 0.091 & $\mathrm{MS}_{2}=2.647$ & 0.709 & $\beta_{2}=0.690$ & 0.087 & $\mathrm{MS}_{2}=2.239$ & 0.695 \\
\hline Religion & $\mathrm{M}_{3}$ & $\beta_{3}=0.536$ & 0.121 & $\mathrm{MS}_{3}=2.125$ & 0.411 & $\beta_{3}=0.547$ & 0.117 & $\mathrm{MS}_{3}=2.095$ & 0.426 & $\beta_{3}=0.528$ & 0.127 & $\mathrm{MS}_{3}=2.143$ & 0.421 \\
\hline $\begin{array}{l}\text { Appropriateness of } \\
\text { taking actions }\end{array}$ & $\mathrm{M}_{4}$ & $\beta_{4}=0.868$ & 0.095 & $\mathrm{MS}_{4}=2.679$ & 0.516 & $\beta_{4}=0.881$ & 0.091 & $\mathrm{MS}_{4}=2.759$ & 0.511 & $\beta_{4}=0.853$ & 0.094 & $\mathrm{MS}_{4}=2.627$ & 0.527 \\
\hline $\begin{array}{l}\text { Employee's } \\
\text { motivation }\end{array}$ & $\mathrm{M}_{5}$ & $\beta_{5}=0.864$ & 0.173 & $\mathrm{MS}_{5}=2.660$ & 0.698 & $\beta_{5}=0.918$ & 0.164 & $\mathrm{MS}_{5}=2.781$ & 0.654 & $\beta_{5}=0.816$ & 0.153 & $\mathrm{MS}_{5}=2.539$ & 0.657 \\
\hline $\begin{array}{l}\text { Employee's } \\
\text { honesty }\end{array}$ & $\mathrm{M}_{6}$ & $\beta_{6}=0.597$ & 0.162 & $\mathrm{MS}_{6}=2.509$ & 0.882 & $\beta_{6}=0.749$ & 0.152 & $\mathrm{MS}_{6}=3.141$ & 0.914 & $\beta_{6}=0.448$ & 0.169 & $\mathrm{MS}_{6}=2.124$ & 0.763 \\
\hline $\begin{array}{l}\text { Resistance to } \\
\text { change }\end{array}$ & $\mathbf{M}_{7}$ & $\beta_{7}=0.634$ & 0.159 & $\mathrm{MS}_{7}=2.188$ & 0.551 & $\beta_{7}=0.564$ & 0.146 & $\mathrm{MS}_{7}=2.301$ & 0.497 & $\beta_{7}=0.697$ & 0.138 & $\mathrm{MS}_{7}=2.064$ & 0.568 \\
\hline $\begin{array}{l}\text { Fear of behaviour } \\
\text { control by others }\end{array}$ & $\mathrm{M}_{8}$ & $\beta_{8}=0.468$ & 0.095 & $\mathrm{MS}_{8}=2.445$ & 0.503 & $\beta_{8}=0.491$ & 0.091 & $\mathrm{MS}_{8}=2.667$ & 0.542 & $\beta_{8}=0.426$ & 0.083 & $\mathrm{MS}_{8}=2.354$ & 0.429 \\
\hline
\end{tabular}


APPENDIX II: APPLICATION QUESTIONNAIRE

University of $\mathrm{xxx}$

xxx Research Centre

xxx Business School

Application Questionnaire

Evaluating semiotic interoperability that enables information sharing between business processes

Meeting

Date

Bearing in mind your experience including your current views and/or the views during the previous interview, please circle the most adequate answer and comment further if needed: 


\section{Evaluation at Technical Level}

Please follow the guidelines provided below and answer the corresponding questions.

\begin{tabular}{|c|c|}
\hline Technical metric & Solution approach/method/tool \\
\hline \multicolumn{2}{|c|}{ Modelling business document } \\
\hline Components model & $\begin{array}{l}\text { Business document is the basis of systems integration; it contains } \\
\text { information regarding service definition, service interface, and } \\
\text { technical specification. It can be modelled by specific tools (e.g. } \\
\text { XML Spy, Maestro, XML Editing Tools). The metrics address } \\
\text { questions whether the business document has been modelled (e.g. } \\
\text { High-level model, Components model) or not. }\end{array}$ \\
\hline \multicolumn{2}{|c|}{ Implementation of data integration } \\
\hline $\begin{array}{l}\text { Source and target data } \\
\text { format definition }\end{array}$ & $\begin{array}{l}\text { Addressing questions whether both source data format and target } \\
\text { data format have been defined. }\end{array}$ \\
\hline $\begin{array}{l}\text { Data } \\
\text { transf }\end{array}$ & $\begin{array}{l}\text { Addressing questions whether data integration has been } \\
\text { implemented, including the steps of data mapping and data } \\
\text { transformation. If yes, any specific tools e.g. STEP, Mapper are } \\
\text { used. }\end{array}$ \\
\hline \multicolumn{2}{|c|}{ Implementation of service integration } \\
\hline $\begin{array}{l}\text { Services for } \\
\text { connecting processes } \\
\text { Services for message } \\
\text { exchange }\end{array}$ & $\begin{array}{l}\text { Addressing questions whether the service integration has been } \\
\text { implemented for connecting processes and message exchange, and } \\
\text { if yes, any specific tools such as Model-driven development (e.g. } \\
\text { PIM4SOA, Maestro, Gabriel) are used. }\end{array}$ \\
\hline $\begin{array}{l}\text { Deployment on } \\
\text { execution } \\
\text { infrastructure }\end{array}$ & $\begin{array}{l}\text { Addressing questions whether execution infrastructure has been } \\
\text { deployed; if yes, any specific tools, e.g. Respective execution } \\
\text { infrastructure: SOA (e.g. Johnson), agents (e.g. JACK), peer-to- } \\
\text { peer (e.g. WS Execution Engine) are used. }\end{array}$ \\
\hline \multicolumn{2}{|l|}{ Business semantics } \\
\hline Semantic conversion & $\begin{array}{l}\text { Business semantic addresses the issue of defining a common } \\
\text { terminology and understanding of the information to be exchanged } \\
\text { between business processes. The metrics address questions whether } \\
\text { there is conflict in business semantics, and, if yes, any specific tools } \\
\text { or methods (e.g. OWL-S, ARGOS, ATHOS, semaphore, Protégé) } \\
\text { are used. }\end{array}$ \\
\hline
\end{tabular}




\section{Evaluation at Formal Level}

Please follow the guidelines provided below and answer the corresponding questions.

\begin{tabular}{|c|c|}
\hline $\begin{array}{l}\text { Formal metric } \\
\text { (performance measure) }\end{array}$ & Solution approach/method/tool \\
\hline \multicolumn{2}{|l|}{ Business strategy } \\
\hline Clarity in strategic goals & $\begin{array}{l}\text { Addressing questions such as the presence of conflict in } \\
\text { understanding the strategic purpose of collaboration and, if yes, } \\
\text { whether these have been adequately resolved. Solution } \\
\text { approaches and tools: e.g. Enterprise modelling (e.g. ARIS, } \\
\text { GraiTools, Mo2Go, METIS); Exchange of enterprise models. }\end{array}$ \\
\hline $\begin{array}{l}\text { Formal commitment to } \\
\text { prevent termination or } \\
\text { premature collaboration }\end{array}$ & $\begin{array}{l}\text { tment to clarify the } \\
\text { re collaboration. }\end{array}$ \\
\hline Backup strategic plan & th backup plans to prevent \\
\hline \multicolumn{2}{|c|}{ Management of external relationships } \\
\hline Partner selection & here are mechanisms to identify the best \\
\hline Partner assessment & $\begin{array}{l}\text { whether there are guidelines developed on partners' } \\
\text { measurement. }\end{array}$ \\
\hline Operation contracts & $\begin{array}{l}\text { Addressing whether there are clear, well-defined cooperation } \\
\text { contracts with partners, spelling out conditions and liabilities. }\end{array}$ \\
\hline Conflict resolution & Addressing whether there are mechanisms to deal with conflict. \\
\hline Communication & $\begin{array}{l}\text { Addressing whether there are methods for overcoming } \\
\text { communication barriers with partners. }\end{array}$ \\
\hline
\end{tabular}

Collaborative business processes management

Clarity in responsibility

Addressing whether there is clear division of responsibility between stakeholders involved between processes.

Business process modelling

Addressing whether there are BPM tools (e.g. XPDL, ARIS EPC, BPMN, BPEL, GraiTools, Maestro, METIS, MoGo) used for articulation of processes.

Clarity in business

Addressing whether there are documents/statements that clearly process define the processes and their responsibilities.

Process visibility Addressing whether the status of each step in one process is visible to the other process.

IPR management

IPR protection

Addressing whether a collaboration agreement clarifies the IPRs to be provided by departments involved in the process and the conditions of use and compensation are clearly agreed.

Potential IPR Addressing whether potential IPRs emerging from the collaboration will be identified beforehand, and the use and sharing of rights has been agreed.

IPR conflict Addressing whether there is clear agreement on solving conflict related to IPR-sharing or use implied in the collaboration.

Organisational structure

Role mapping

Addressing whether there is clarity appointing the liaison person for various types of issues. 


\section{Evaluation at Informal Level}

Please follow the guidelines provided below and answer the corresponding questions.

\begin{tabular}{|c|c|}
\hline $\begin{array}{l}\text { Informal metric } \\
\text { (indicator) }\end{array}$ & Solution approach/method/tool \\
\hline Tradition and culture & $\begin{array}{l}\text { Addressing whether there is tradition/culture difference that } \\
\text { affects the collaboration. Solution method such as culture } \\
\text { valuation (e.g. CAVA-AI framework (Al-Rajhi, 2012)). }\end{array}$ \\
\hline Management style & $\begin{array}{l}\text { Addressing whether there is a management style difference } \\
\text { that affects the collaboration. }\end{array}$ \\
\hline Religion & $\begin{array}{l}\text { Addressing whether there is religious difference that affects the } \\
\text { collaboration. }\end{array}$ \\
\hline $\begin{array}{l}\text { Appropriateness of taking } \\
\text { action }\end{array}$ & $\begin{array}{l}\text { Addressing whether there is inappropriateness in taking action } \\
\text { that affects the collaboration. }\end{array}$ \\
\hline Employee's motivation & $\begin{array}{l}\text { Addressing questions whether the involved employees from } \\
\text { different departments are motivated, or whether there are } \\
\text { incentives and encouragement for improving their initiatives. }\end{array}$ \\
\hline Employee's honesty & $\begin{array}{l}\text { Addressing whether the employees involved in different } \\
\text { departments share the same level of honesty and openness, and } \\
\text { how much this factor affects an especially confidential } \\
\text { collaboration project. }\end{array}$ \\
\hline Resistance to change & $\begin{array}{l}\text { Addressing whether employees are willing to accept changes } \\
\text { to their existing workflow. }\end{array}$ \\
\hline $\begin{array}{l}\text { Fear of behaviour control } \\
\text { by others }\end{array}$ & $\begin{array}{l}\text { Addressing whether the involved employees are afraid of being } \\
\text { controlled by others during the collaboration. }\end{array}$ \\
\hline
\end{tabular}

